Portolés J1, Romero ML*, Filippou FC and Bonet JL, Simulation and design recommendations of eccentrically loaded slender concrete-filled tubular columns, Engineering Structures 2011: 33 (5), pp. 1576-1593.

\title{
Simulation and design recommendations of eccentrically loaded slender
}

\section{concrete-filled tubular columns.}

\author{
J.M. Portolés ${ }^{\mathrm{a}}$, M.L. Romero ${ }^{\mathrm{b} *}$, F.C. Filippou ${ }^{\mathrm{c}}$ and J.L. Bonet ${ }^{\mathrm{b}}$
}

a Department of Mechanical Engineering and Construction, Universitat Jaume I, Castellón, Spain

b Instituto de Ciencia y Tecnología del Hormigón (ICITECH), Universidad Politécnica de Valencia, Spain

c Civil and Environmental Engineering Department. University of California at

$$
\text { Berkeley, USA }
$$

\begin{abstract}
This paper proposes an efficient numerical model for the simulation of the behavior of slender circular concrete-filled tubular columns subjected to eccentric axial load with single curvature, for the cases of both normal and high strength concrete. The paper focuses on the study of the influence that the variables affecting beam-column behavior (length and relative slenderness) and the variables affecting section behavior (diameter/thickness ratio, mechanical capacity of steel) have on the overall buckling of this type of column. An extended parametric study is carried out to propose design recommendations, primarily to establish the importance of the use of high strength concrete compared with that of normal strength concrete. The results show that for slender elements the optimum design is reached when the mechanical capacity of the steel is slightly lower than that of the concrete contribution.
\end{abstract}

Keywords: numerical model, composite column, concrete-filled tubular columns, high strength concrete, buckling.

*Corresponding author: Tel: +34-963877007(ext: 76742) Fax: +34-963879679, e-mail address: mromero@mes.upv.es 
Portolés J1, Romero ML*, Filippou FC and Bonet JL, Simulation and design recommendations of eccentrically loaded slender concrete-filled tubular columns, Engineering Structures 2011: 33 (5) , pp. 1576-1593.

\section{NOTATION}

$\mathrm{e}=$ eccentricity

$\mathrm{L}=$ length

$\mathrm{D}=$ diameter

$\mathrm{t}=$ thickness

$f_{c}=$ strength of concrete

$\mathrm{f}_{\mathrm{y}}=$ yielding stress of steel

CXXX-T-L-FF-EE-1 (i.e. C125-5-3-90-50-1), where C stands for circular, XXX is the diameter in $\mathrm{mm}, \mathrm{T}$ the thickness in $\mathrm{mm}, \mathrm{L}$ the nominal length in meters, FF the nominal concrete strength in $\mathrm{MPa}$, and $\mathrm{EE}$ is the eccentricity applied.

$\mathrm{CFT}=$ concrete-filled tubular columns

$\mathrm{NSC}=$ normal strength concrete

$\mathrm{HSC}=$ high strength concrete.

$\mathrm{CCR}=$ concrete contribution ratio

$\mathrm{SI}=$ strength index

Ac $=$ area of concrete

As $=$ area of steel

$E \cdot I=$ effective flexural stiffness of the composite section.

$$
\bar{\lambda}=\text { relative slenderness }=\sqrt{\frac{N_{p l}}{N_{c r}}}=\sqrt{\frac{A_{c} f_{c}+A_{s} f_{y}}{\frac{\pi^{2} E I}{L^{2}}}}
$$


Portolés J1, Romero ML*, Filippou FC and Bonet JL, Simulation and design recommendations of eccentrically loaded slender concrete-filled tubular columns, Engineering Structures 2011: 33 (5) , pp. 1576-1593.

\section{INTRODUCTION}

Recent years have seen an increase in the use of concrete-filled tubular columns due to their high stiffness, ductility and fire resistance. In addition, high strength concrete is widely used in building columns to reduce the size of the cross section. Since most experimental studies on eccentrically loaded slender columns are limited to normal strength concrete, there is a need for information regarding the response of this type of structural member towards high strength concrete.

In order to address this lack of information the authors established an integrated experimental and analytical study consisting of the following tasks: an extensive set of experiments on eccentrically loaded slender columns [1], the development of a computationally-efficient analytical model, parametric studies on the influence of key parameters, and the development of design recommendations.

This paper provides a brief presentation of the development of the numerical model but focuses on the two remaining tasks. The aim is to obtain as accurate and reliable a method as possible for performing an extended parametric study with reduced time consumption. The purpose of this is to provide some design recommendations to establish the importance of the use of high strength concrete compared with that of normal strength concrete.

In fact, the design codes for each country provide simplified methods for composite columns, but these are generally limited to the use of concrete with a cylinder strength no higher than 50-60 MPa, as in the case of Eurocode 4 (EC4) [2], and ought to be revised accordingly. This is crucial given that in the practical design of a column within a building the axial load, eccentricity and height of the storey are fixed. In this situation 
Portolés J1, Romero ML*, Filippou FC and Bonet JL, Simulation and design recommendations of eccentrically loaded slender concrete-filled tubular columns, Engineering Structures 2011: 33 (5) , pp. 1576-1593.

if HSC is used, rather than normal strength concrete (NSC), the section is reduced and the slenderness increased, so the element experiences higher geometric nonlinearity.

Johansson and Gylltoft [3],[4], and Zeghiche and Chaoui [5], have demonstrated that it is possible to use high strength concrete and still achieve structural ductile behavior. However, if the aim is to obtain the same ductility as with NSC, a greater wall thickness is required to complement the HSC core of the column.

If the column is slender and is subjected to an eccentric load it seems clear that the increasing curvature in the cross section and the increase in flexure are to the detriment of any improvement in the concrete strength due to the confinement effect [3]. O'Shea and Bridge [6], however, stated that when eccentricity is increased in short columns, ductility also improves. This statement needs to be amplified for slender columns, as there are not many studies on high performance materials for CFTs, focusing on overall buckling. Han [7] studied tubular columns with a high slenderness ratio and normal strength concrete, concluding that the strength of the concrete has very little influence on the ultimate capacity as the failure load is governed by the flexural rigidity.

Sakino et al. [8] and Fujimoto et al. [9] concluded, in the case of short columns, that the use of HSC reduces the ductility of circular CFT. However, this can be improved in two ways, by using low values of $\mathrm{D} / \mathrm{t}$ or increasing the strength of the steel $\left(\mathrm{f}_{\mathrm{y}}\right)$.

Grauers [10] obtained more ductile behavior introducing a small eccentricity and Bergman [11] observed non-ductile behavior once the maximum load was reached. He studied the confinement mainly for normal strength concrete and partially for high strength concrete, but applying only axial load and not eccentricity. 
Portolés J1, Romero ML*, Filippou FC and Bonet JL, Simulation and design recommendations of eccentrically loaded slender concrete-filled tubular columns, Engineering Structures 2011: 33 (5) , pp. 1576-1593.

Varma et al. [12] asserted that the curvature ductility of high strength square CFT beam-columns (with a length of 1.5 meters) decreased significantly with an increase in either the axial load level or the $\mathrm{b} / \mathrm{t}$ ratio of the steel tube.

Zeghiche and Chaoui [5] stated that the increase of concrete core strength is only effective for shorter columns and decreases with increasing $\mathrm{L} / \mathrm{D}$. The $\mathrm{D} / \mathrm{t}$ ratio, which is one of the parameters that can improve ductile behavior, was not varied in their tests.

Portolés et al. [1] concluded it was clear that the use of HSC in concrete-filled tubular columns does not offer the same improvement as that of NSC in composite behavior. However, it is possible to achieve ductile behavior by employing a proper set of parameters for the section $(\mathrm{D} / \mathrm{t}$, fy and $\mathrm{fc})$, together with a proper set of parameters for the whole member (L/D and e/D), all of which are decisive for the behavior of the member. Different performance indexes were used to study the effects of the main variables on the load-carrying capacity and ductility. These led to the conclusion that it was necessary to provide more data to achieve reliable results. To do so a numerical model for the accurate prediction of high strength concrete composite columns was needed.

The aim of this paper is to establish design recommendations for the use of high strength concrete as opposed to that of normal strength concrete through the comparison of two performance indexes: concrete contribution ratio and strength index. Although ductility is also an interesting issue in concrete-filled columns, the authors chose not to include it in this paper so as to avoid excessive complication.

The final objective is to provide guidance when specifying the design for the best performing slender CFST columns, both for normal and high strength concrete. 
Portolés J1, Romero ML*, Filippou FC and Bonet JL, Simulation and design recommendations of eccentrically loaded slender concrete-filled tubular columns, Engineering Structures 2011: 33 (5) , pp. 1576-1593.

\section{NUMERICAL MODEL}

\subsection{Introduction.}

In general, there are three different types of numerical models for the simulation of CFT columns [13]: a) three-dimensional finite element model; b) fiber beam-column elements; and c) concentrated plasticity column elements.

As the main interest of this paper focuses on a computationally efficient element for conducting extensive parametric studies, the three-dimensional finite element models will not be pursued. While concentrated plasticity models are very efficient they suffer from some limitations as regards aspects important for this project: the need to calibrate a yield surface under biaxial bending and axial force and the development of evolution rules for hardening and softening response for non-associative plasticity. For this reason this type of model is not pursued further in this study, although Hajjar et al. [14] presented a thorough study showing the potential of this model.

A beam finite element was selected, given that the final objective of this project is both the development of design recommendations for slender high strength concrete-filled tubular (CFT) columns, and the development of analytical models for nonlinear simulation of large structures.

For fiber column elements, the review study by Spacone and El-Tawil [13] contains information on available frame elements, section models, with lumped and distributed inelasticity, as well as models with perfect and partial connections.

However, recent interest has focused on the introduction of high strength concrete in this type of structure. In fact, it can be stated that extensive work has been done on nonlinear finite element analysis for normal strength concrete, although the number of 
Portolés J1, Romero ML*, Filippou FC and Bonet JL, Simulation and design recommendations of eccentrically loaded slender concrete-filled tubular columns, Engineering Structures 2011: 33 (5) , pp. 1576-1593.

studies on high strength concrete is considerably lower. Romero et al. [15] presented a review of the latest formulations.

The fiber models are simpler as their material constitutive models are one-dimensional despite the fact that the element itself is three-dimensional, with nonlinearity distributed along the element. These elements can be classified into three general families in terms of the method of interpolation: displacement-, force-, and mixed-based. Displacementbased frame elements are quite simple and easy to implement, but suffer from limitations when yielding concentrates at a specific location, as the assumption of cubic displacements (and thus linear curvatures) is exact for an Euler-Bernoulli beam only in the linear elastic range and for constant cross sections. Nonetheless, they are popular due to their ease of implementation, and De Sousa and Caldas [16] used a cubic interpolation of transverse displacements and quadratic interpolation for axial displacements obtaining suitable results with no more than four elements per column.

Initially, a perfect bond between the concrete core and steel tube was assumed in most of the displacement-based models, but Hajjar et al. [17] proposed a numerical model for rectangular columns that accounted for slip between concrete and steel components. According to this study slip has an important effect on the transmission of loads in the composite joints but has little effect on the global behavior of CFT columns.

In the two-node Euler-Bernoulli force-based frame element, the beam section forces are expressed as functions of the nodal forces through force interpolation functions. The force-based element is rather appealing as it is exact within the small-deformation Euler-Bernoulli beam theory, Spacone et al. [18].

With this model it is possible to represent geometric nonlinearity within a structural member by subdividing it into 2 or 4 elements and using the co-rotational formulation 
Portolés J1, Romero ML*, Filippou FC and Bonet JL, Simulation and design recommendations of eccentrically loaded slender concrete-filled tubular columns, Engineering Structures 2011: 33 (5), pp. 1576-1593.

to transform the nodal variables on account of large displacements. A more complex alternative approach is the development of a force-based element that includes the effect of geometric nonlinearity due to moderate deformations, as pursued by Neuenhofer and Filippou [19] for elastic, and De-Souza[20] for inelastic response. Valipour and Foster [21] recently pursued a similar approach. Ayoub and Filippou [22] and Limkatanyu and Spacone [23] proposed a beam element which includes the effect of relative slip between steel and concrete.

Spacone et al. [24] were the first to propose a mixed formulation for the beam finite element. Taylor et al. [25] finally demonstrated the consistent derivation of such an element with the $\mathrm{Hu}$-Washizu variational principle and its consistent numerical implementation. Pi et al. [26] used a mixed formulation and proposed a total Lagrangian finite element for both composite beams and columns, introducing an independent displacement to reproduce the slip between the steel and concrete. Tort and Hajjar [27] also presented a mixed finite-element model for rectangular concrete-filled steel tube members.

Previous studies have shown that the behavior of CFT columns depends on several parameters which can be grouped into geometric or material categories. It is relatively easy to include the geometric parameters in a computational model but it is more difficult to find the rational description of the material effects in a beam element. The decision was made to start the investigation with a readily available beam column element with simple assumptions and later refine it if the correlation studies proved this necessary.

The numerical model must be valid for simulating the behavior of slender circular concrete-filled tubular columns subjected to eccentric axial load with single curvature, 
Portolés J1, Romero ML*, Filippou FC and Bonet JL, Simulation and design recommendations of eccentrically loaded slender concrete-filled tubular columns, Engineering Structures 2011: 33 (5) , pp. 1576-1593.

both for normal and high strength concrete. The material constitutive model is uniaxial and the finite element uses a co-rotational formulation with a force interpolation iterative scheme and a fiber integration of the cross section. The results from the literature reviewed show that, for slender columns subjected to axial load with eccentricity, the second order effects and overall buckling have a great influence on the numerical model, and the concrete is not confined until the post-peak behavior stage.

This type of element is available in the OpenSees platform [28] and in FedeasLab [29], a Matlab-based toolbox for the nonlinear analysis of structures. The assumptions of the beam column element available are:

- The element is based on the Euler-Bernoulli beam theory under small deformations.

- Perfect bond in the longitudinal direction between the concrete core and the steel tube is assumed. Consequently, the interlayer slip displacement is not accounted for. This assumption was made to avoid a complication which is not clear that is necessary for slender columns, Hajjar et al. [17].

- Perfect compatibility is also assumed in the radial direction. This is a rough approximation as the Poisson ratio of the concrete core is lower than that of the steel tube for small strain values [30]. However, the oval deformation of the cross section due to the eccentricity of the load introduces significant complexity with unclear significance for slender columns.

- Local buckling of the steel tube is neglected, because all the cases analyzed have a thickness greater than the minimum set in Eurocode 4 [2]. The maximum D/t ratio equals $90(235 /$ fy). 
Portolés J1, Romero ML*, Filippou FC and Bonet JL, Simulation and design recommendations of eccentrically loaded slender concrete-filled tubular columns, Engineering Structures 2011: 33 (5), pp. 1576-1593.

- The section is discretized into fibers with uniaxial material relationships for steel and concrete that will be discussed in detail in a later section.

- The limitations of the model are the following: columns with an L/D ratio higher than 8 , ratios of e/D from 0.05 to 0.5 , strength of concrete up to $100 \mathrm{MPa}$ and strength of steel up to $435 \mathrm{MPa}$.

\subsection{Experimental tests for validation.}

The model was validated with comparisons of results from experiments by the authors [1] and different cases from the literature, summarized in Romero et al. [33].

From many tests in the literature only the data regarding maximum load can be obtained while the entire force-displacement curve is available from the tests by the authors. The former will be used to check the reliability of the numerical model, while the latter are used for the complete validation of the model.

\subsection{1.- Tests from experiments by the authors.}

These tests are described briefly in the following. The full details can be found in Portolés et al. [1]. Thirty-seven tests were carried out on normal and high strength CFT columns, with three of these being repeated to check consistency, so that thirty-four different cases are listed in Table 1. These tests were designed to investigate the effect of four main parameters on the column behavior: slenderness (L/D), diameter to thickness ratio $(D / t)$, strength of concrete $\left(f_{c}\right)$ and eccentricity $\left(e_{0}\right)$. The ranges of these parameters were selected with respect to current construction practices, including high strength concrete and high eccentricities, which are less common. Table 1 summarizes the experimental data. The column lengths were $2135 \mathrm{~mm}$ and $3135 \mathrm{~mm}$, for tube lengths of $2000 \mathrm{~mm}$ and $3000 \mathrm{~mm}$, respectively, allowing for the length of the end plates used in the special assembly. The nominal cross section of the circular tubes 
Portolés J1, Romero ML*, Filippou FC and Bonet JL, Simulation and design recommendations of eccentrically loaded slender concrete-filled tubular columns, Engineering Structures 2011: 33 (5), pp. 1576-1593.

$($ diameter $\mathrm{D} \times$ thickness $\mathrm{t}$ ) measured $100 \times 3 \mathrm{~mm}, 100 \times 5 \mathrm{~mm}, 125 \times 5 \mathrm{~mm}$, and $160 \times$ $6 \mathrm{~mm}$. The thickness of the tubes was such that local buckling was avoided following Eurocode 4. The nominal strength of concrete varied from 30, 70 to $90 \mathrm{MPa}$ and in some cases empty columns were tested as reference. The axial load was applied with the same eccentricity at both ends with a value of 20 or $50 \mathrm{~mm}$, which meant that the columns were subjected to single curvature bending. The tests are identified according to:

CXXX-T-L-FF-EE-1 (i.e. C125-5-3-90-50-1), where C stands for circular, XXX is the nominal diameter in $\mathrm{mm}, \mathrm{T}$ the thickness in $\mathrm{mm}, \mathrm{L}$ the nominal length in meters, FF the nominal concrete strength in MPa, and EE is the eccentricity applied.

The steel grade was S275JR and the actual strength $\left(\mathrm{f}_{\mathrm{y}}\right)$ of the empty tubes was obtained by coupon test. The yielding stress was between 320 and $325 \mathrm{MPa}$ for all cases. The modulus of elasticity Es of the steel was set following European standards with a value of $210 \mathrm{GPa}$.

The concrete compressive strength $\mathrm{f}_{\mathrm{c}}$ was determined from both the $150 \times 300 \mathrm{~mm}$ cylinders and the $100 \mathrm{~mm}$ cubes using standard tests. The strength of the cubic samples was interpreted for the cylindrical equivalent using Eurocode 2.

Five LVDTs were used to symmetrically measure the deflection of the column at mid length $(0.5 \mathrm{~L})$ and also at four additional levels $(0.25 \mathrm{~L}, 0.37 \mathrm{~L}, 0.625 \mathrm{~L}, 0.75 \mathrm{~L})$. Once the specimen was put in place, it was tested with displacement control in order to measure post-peak behavior.

\subsection{2.- Tests by other authors.}


Portolés J1, Romero ML*, Filippou FC and Bonet JL, Simulation and design recommendations of eccentrically loaded slender concrete-filled tubular columns, Engineering Structures 2011: 33 (5), pp. 1576-1593.

A comparison with 52 experimental tests from the literature was performed in this paper. The tests were from Zeghiche and Chaoui [34], Rangan and Joyce [35], Neogi et al. [36], and Kilpatrick and Rangan [37] .

\subsection{Sensitivity analysis.}

In this section a sensitivity analysis of the numerical model is carried out in order to establish which parameters primarily influence the numerical model.

\subsubsection{Constitutive Models.}

The concrete confined in a short concrete-filled tubular column is in a triaxial stress state, while the steel is in a biaxial state. Under these multiaxial stress conditions the concrete strength and ductility increase while steel strength decreases. If uniaxial stressstrain relations are selected for both materials for the sake of simplicity, then this behavior must be accounted for. Complicating matters further, the column slenderness or the large eccentricity of loading produces a non-uniform confinement of the concrete that may need to be included.

a) Steel model

The stress-strain relationship of cold-formed hollow tubes is well represented by the Giuffre-Menegotto-Pinto model [38] with its gradual transition from a linear elastic to a post-yield hardening branch.

The equation of this model is defined by four parameters, elastic modulus $\mathrm{E}$, the yielding stress fy, the hardening modulus of yielded steel $E_{h}$, and the index $r$. This index has effects on the curvature of the diagram:

$$
Y=b X+(1-b) \frac{X}{\left(1-|X|^{r}\right)^{\frac{1}{r}}} \text {, }
$$

where $\varepsilon_{\mathrm{y}}=\frac{\mathrm{f}_{\mathrm{y}}}{\mathrm{E}}, \mathrm{b}=\frac{\mathrm{E}_{\mathrm{h}}}{\mathrm{E}}, \mathrm{X}=\frac{\varepsilon}{\varepsilon_{\mathrm{y}}}, \sigma=\mathrm{f}_{\mathrm{y}} \mathrm{Y}$ 
Portolés J1, Romero ML*, Filippou FC and Bonet JL, Simulation and design recommendations of eccentrically loaded slender concrete-filled tubular columns, Engineering Structures 2011: 33 (5), pp. 1576-1593.

The elastic modulus of steel was assumed to be equal to $\mathrm{E}=210 \mathrm{GPa}$, while the remaining parameters were determined from the hollow tube experiments. Figure 1.a shows a graph of the steel stress-strain relation that was used in the correlation of the response of a hollow column test in Figure 1.b. The horizontal axis presents the lateral deflection of the mid-span section.

b) Concrete model

For short columns one of the first numerical models for CFT columns was developed and formulated for normal strength concrete and for rectangular CFT columns by Tomii and Sakino [39]. They stated that in square or rectangular CFT columns the confinement was not important due to the non-constant lateral pressure on the concrete core, and the model did not increase the strength of concrete but improved the post-peak descending behavior in terms of the diameter-to-thickness ratio.

Several authors, such as Shams and Saadeghvaziri [40], Susantha et al. [41], Hatzigeorgiou [42], Xiao et al. [43], and $\mathrm{Hu}$ et al. [44], proposed new models for circular columns which account for the strength and the ductility enhancement of the concrete. These models are based on the well-known studies by Richart et al [45] where the confined concrete strength depends on the mean confining stress and a confinement factor $\mathrm{k}$, which ranges from 4 to 6 .

Nakahara et al. [46] updated fiber $\sigma-\varepsilon$ curves for high strength materials and Uy [47] developed fiber models for conventional strength CFTs made from thin-walled steel tubes.

However, these models are limited to short columns subjected to loading with small eccentricity. Recently Hatzigeorgiou [48], Liang [49], Hu et al. [50] and Liang and 
Portolés J1, Romero ML*, Filippou FC and Bonet JL, Simulation and design recommendations of eccentrically loaded slender concrete-filled tubular columns, Engineering Structures 2011: 33 (5), pp. 1576-1593.

Frangomeni [51] proposed models for short columns under axial load and bending moment.

But if the structural member is slender and the second order effects are significant, the eccentricity of the axial force at the critical section is so large that the confinement effect on the concrete is insignificant, as also concluded by Hajjar and Gourley [52], and Liang [53]. In contrast, the descending branch of the concrete stress-strain relation is critical for the representation of the softening behavior of the post-peak of the slender CFT columns. Clearly, the softening response is very sensitive to the numerical solution scheme. When the concrete core starts to crush, its dilatation reaches the steel value, and the resulting contact of the two materials produces a confinement effect. This was observed by Tomii and Sakino [39] for square columns but is also applicable in the case of slender circular columns with high eccentricity or slenderness.

In order to validate a general beam column fiber model, but for square columns, Varma et al. [54] used a three-dimensional finite element model for the failure segment of a high strength square CFT subjected to concentric axial compressive loading. They used their own stress-strain relationship for the confined concrete.

However, most of the previous studies concentrated on short columns and the study of the influence of high strength concrete for slender columns subjected to eccentric loading was not completely established.

Therefore, the authors decided to use a combination of two models for this paper. The ascending branch is based on the model of Collins et al. [55] for concrete valid for NSC and HSC without confinement. The post-peak behavior is represented by the model from Tomii and Sakino [39] which accounts for the effect of the D/t ratio on the softening slope. The tensile strength is ignored. This model was first proposed by 
Portolés J1, Romero ML*, Filippou FC and Bonet JL, Simulation and design recommendations of eccentrically loaded slender concrete-filled tubular columns, Engineering Structures 2011: 33 (5), pp. 1576-1593.

Hajjar and Gourley [52] for NSC. Figure 2 shows the concrete model for different D/t ratios and different strengths of concrete.

Once the maximum concrete strength is reached, it remains constant up to a strain of $\varepsilon_{\mathrm{c} 1}=0.005$. For larger compressive strains, concrete stress remains constant if the $\mathrm{D} / \mathrm{t}$ ratios are equal or lower than 24 . For larger $\mathrm{D} / \mathrm{t}$ ratios the concrete stress decreases with increasing compressive strain to a residual value $\left(\sigma_{\text {res }}\right)$ at a strain $\varepsilon_{\mathrm{cl}}=0.015$. According to the following equation, this residual stress depends on the $\mathrm{D} / \mathrm{t}$ ratio up to a maximum value of $\mathrm{D} / \mathrm{t}=64$, where it becomes zero. The residual stress is given by the following equations:

$$
\sigma_{\text {res }}=\left\{\begin{array}{l}
f_{c} \quad \frac{D}{t} \leq 24 \\
f_{c}\left(1.6-0.025 \frac{D}{t}\right) \quad 24<\frac{D}{t} \leq 64 \\
0 \quad 64<\frac{D}{t}
\end{array}\right.
$$

The equations are:

$\sigma=\left\{\begin{array}{l}0 \quad \varepsilon_{\mathrm{c}} \leq 0 \\ \mathrm{f}_{\mathrm{c}} \frac{\mathrm{X} \cdot \mathrm{n}}{\mathrm{n}-1+\mathrm{X}^{\mathrm{n} \cdot \mathrm{k}}} \quad 0<\varepsilon_{\mathrm{c}} \leq \varepsilon_{\mathrm{c} 0} \\ \mathrm{f}_{\mathrm{c}} \quad \varepsilon_{\mathrm{c} 0}<\varepsilon_{\mathrm{c}} \leq \varepsilon_{\mathrm{c} 1} \\ \mathrm{f}_{\mathrm{c}}+\left(\sigma_{\mathrm{res}}-\mathrm{f}_{\mathrm{c}}\right) \frac{\varepsilon_{\mathrm{c}}-\varepsilon_{\mathrm{c} 1}}{\varepsilon_{\mathrm{c} 2}-\varepsilon_{\mathrm{c} 1}} \quad \varepsilon_{\mathrm{c} 1}<\varepsilon_{\mathrm{c}} \leq \varepsilon_{\mathrm{c} 2} \\ \sigma_{\text {res }} \quad \varepsilon_{\mathrm{c} 2}<\varepsilon_{\mathrm{c}}\end{array}\right.$

where $\mathrm{E}_{\mathrm{c}}=3320 \sqrt{\frac{\mathrm{f}_{\mathrm{c}}}{6900}} ; \quad \mathrm{n}=0.8+\frac{\mathrm{f}_{\mathrm{c}}}{17} ;$ with $\mathrm{f}_{\mathrm{c}}$ in $\mathrm{MPa}$

$$
\varepsilon_{\mathrm{c}}=-\varepsilon ; \varepsilon_{\mathrm{c} 1}=\frac{\mathrm{f}_{\mathrm{c}}}{\mathrm{E}_{\mathrm{c}}} \frac{\mathrm{n}}{(\mathrm{n}-1)} ; \quad \varepsilon_{\mathrm{c} 1}=0.005 ; \quad \varepsilon_{\mathrm{c} 2}=0.015 ; \quad \mathrm{X}=\frac{\varepsilon_{\mathrm{c}}}{\varepsilon_{\mathrm{c} 1}} ;
$$


Portolés J1, Romero ML*, Filippou FC and Bonet JL, Simulation and design recommendations of eccentrically loaded slender concrete-filled tubular columns, Engineering Structures 2011: 33 (5), pp. 1576-1593.

Figure 3 shows the comparison between two concrete models, the Collins model with a sudden loss of strength which did not converge in the post-peak range, and the HajjarGourley model which captured the post-peak response.

\subsubsection{Finite element model.}

At the beginning of the study the force, displacement and mixed formulation were considered because they were available in the computer program. After an initial evaluation we concluded that the force formulation was the most suitable for the purpose of this study.

a) Number of elements per column.

In the interest of reducing computational time it is important to use the smallest number of finite elements for each column member without affecting the accuracy. It is important to use an even number of elements for each member so as to have a node at mid height of the slender column where the maximum eccentricity occurs. From the numerical tests it was decided that only four elements were needed to obtain results accurate enough (within $3 \%$ deviation from the results of detailed analyses).

b) Discretization of the section.

The integration of the internal forces in the Gauss integration points is performed repeatedly during the iterative process and needs to be optimized, as it consumes at least one third of the total computational time, Romero et al. [56].

Although the same authors, in Bonet et al. [57], have proposed a fast integration algorithm to obtain the stiffness and internal forces of reinforced concrete sections, this is not appropriate if a comparison between strains and local behavior is desired for use in experiments. For this case the integration of the section using fibers was selected. 
Portolés J1, Romero ML*, Filippou FC and Bonet JL, Simulation and design recommendations of eccentrically loaded slender concrete-filled tubular columns, Engineering Structures 2011: 33 (5), pp. 1576-1593.

The section was divided into a regular array of fibers in radial and circumferential directions. The size of the mesh was calibrated in order to obtain sufficient accuracy with the lowest possible amount of fibers. It was noted that with a concrete constitutive model with a sudden change in the strength just prior to the maximum peak, as in Model Code 90 [58] for instance, it was necessary to increase the number of fibers to guarantee convergence, something which was not achieved for high strength concrete. This is due to the fact that a problem of localization appears in the numerical model when softening commences, and all the stresses are suddenly sustained by the steel tube which collapses. However, a concrete model with a more ductile softening branch like the one in Hajjar and Gourley [52] allows convergence.

As a result of this study it was decided that in the radial direction 2 fibers were to be used for the hollow steel section (exterior) and 8 for the concrete core, while in the circumferential direction 16 fibers were selected for both materials.

2.3.4.- Influence of the out-of-straightness imperfections for slender elements.

\section{(Accuracy of the straightness)}

Eurocode 4 [2] introduces an initial imperfection of the column in the design method, since the lack of accuracy of the straightness in real columns as a result of the fabrication process has been proved. EC4 makes it necessary to introduce an initial imperfection of $e_{i m p}=L / 300$, which is perhaps excessive. Galambos and Surovek [59], however, suggest an additional imperfection of $\mathrm{e}_{\text {imp }}=\mathrm{L} / 1000$. It is very difficult to measure this imperfection in laboratory experiments, so the numerical model was used to carry out adjustments.

As the first buckling mode has a sinusoidal deformation, the decision was made to introduce the imperfection in the same way: 
Portolés J1, Romero ML*, Filippou FC and Bonet JL, Simulation and design recommendations of eccentrically loaded slender concrete-filled tubular columns, Engineering Structures 2011: 33 (5), pp. 1576-1593.

$$
y(x)=e_{i m p} \sin \left(\frac{x}{L} \pi\right)
$$

The effect that the variation of initial imperfection has in the force-displacement response for a given column is obvious: when this imperfection increases the maximum load decreases.

The best adjustment between the maximum axial force of the tests and the numerical model is obtained for an initial imperfection of $\mathrm{e}_{\mathrm{imp}}=\mathrm{L} / 600$.

\subsection{Validation of the numerical model.}

This section demonstrates the precision of the numerical model once all the parameters are fixed using a prior sensitivity analysis.

\subsubsection{Force displacement}

Figure 4 shows the comparison of six cases representative of the experimental results and the numerical model with and without introducing the initial imperfections (L/600). As can be observed, the model not only represents the behavior of the column in the ascending branch with sufficient accuracy but also follows the post-peak behavior. It can be inferred that there is a greater difference between both cases in the numerical model (with and without additional imperfection) when the first order eccentricity is lower $(\mathrm{e}=20 \mathrm{~mm})$ or the length is higher $(\mathrm{L}=3 \mathrm{~m})$. This is because it is very important to capture the total eccentricity (first order + second order + additional imperfection) properly, and in such cases the $\mathrm{e}_{\mathrm{imp}}$ is relatively larger than the others.

Figure 5 also shows the comparison of the force-displacement behavior of the experimental cases from Kilpatrick and Rangan [37], with eccentricities varying from 10 to $50 \mathrm{~mm}$, showing excellent accuracy. 
Portolés J1, Romero ML*, Filippou FC and Bonet JL, Simulation and design recommendations of eccentrically loaded slender concrete-filled tubular columns, Engineering Structures 2011: 33 (5), pp. 1576-1593.

\subsection{2.- Failure Load}

a) Tests from experiments by the authors.

The degree of accuracy of the numerical model was compared with the experimental tests as:

$$
\xi=\frac{\mathrm{N}_{\max , \text { Exp }}}{\mathrm{N}_{\text {max,Num }}},
$$

where $\mathrm{N}_{\text {max,Exp }}$ is the maximum axial force of the test and $\mathrm{N}_{\text {max,Num }}$ is the maximum axial force of the numerical model.

The average value presented in Table 1 evidences an average accuracy of 1.02 and a standard deviation of 0.05 , demonstrating the validity of the numerical model.

b) Tests from the literature.

In order to verify the reliability of the proposed numerical model, comparisons with 52 experimental tests from the literature were also performed in this study.

The experimental tests selected correspond to circular tubular columns filled with concrete (CFT) with pinned supports at both ends, and subjected to axial load and uniaxial bending.

Table 2 presents the variation of all parameters for the experimental tests and Table 3 lists the authors of these tests, and the degree of accuracy obtained with the numerical model implemented. From these tables it can be concluded that the model proposed achieves a suitable degree of accuracy and a mean value close to one is reached on the safe side (1.02) with an acceptable variation coefficient (0.13).

\subsection{3.- Factors influencing the accuracy.}

Figure 6.a shows the error in terms of the geometric slenderness $\mathrm{L} / \mathrm{D}$ and the trend line for the tests performed by the authors. It can be observed that the model is on the safe side for greater values of $\mathrm{L} / \mathrm{D}$, which is one of the objectives of the study. If the evolution of the degree of accuracy is studied in terms of D/t, Figure 6.b, this decreases 
Portolés J1, Romero ML*, Filippou FC and Bonet JL, Simulation and design recommendations of eccentrically loaded slender concrete-filled tubular columns, Engineering Structures 2011: 33 (5), pp. 1576-1593.

when $\mathrm{D} / \mathrm{t}$ increases. This occurs when the thickness of the hollow steel section is lower, but even in these cases the average is on the safe side.

For higher eccentricities, the trend line of the degree of accuracy is almost horizontal, Figure 6.c. The same behavior is observed when the influence of the strength of concrete $\left(f_{c}\right)$ is studied, but a higher scatter is observed for high strength concrete cases.

\section{PARAMETRIC STUDIES}

Once the numerical model was validated, it was used to perform a parametric study (in four steps) to complete the partial conclusions achieved in the authors' experimental research described in Portolés et al. [1]. The authors concluded that the use of HSC in concrete-filled tubular columns does not offer the same improvement as that of NSC in composite behavior. However, it was possible to achieve ductile behavior by employing a proper set of parameters for the section $\left(D / t, f_{y}\right.$ and $\left.f_{c}\right)$ together with a proper set of parameters for the whole member (L/D and e/D), all of which are decisive for member behavior. But these tests were limited and it was concluded that to achieve reliable results it was necessary to provide more data.

The first step, step A, focused on studying the effect of the strength of concrete (from $10 \mathrm{MPa}$ to $100 \mathrm{MPa}$ ). We must keep in mind that the study concentrates on slender CFT columns under axial load and eccentric loading with single curvature.

From the results obtained with step A, the decision was made to extend the study to other variables (eccentricity, lengths, diameter to thickness ratio $\mathrm{D} / \mathrm{t}$, etc). Table 4 condenses the range of variables used in each of the parametric studies and the goal set 
Portolés J1, Romero ML*, Filippou FC and Bonet JL, Simulation and design recommendations of eccentrically loaded slender concrete-filled tubular columns, Engineering Structures 2011: 33 (5), pp. 1576-1593.

for each of them. These were denoted as "steps" A, B, C, and D respectively. A total of 706 numerical tests were performed and analyzed.

The sections (diameters and thicknesses) from the experiments [1] were initially used with the intention of extending the partial conclusions to a wider range of cases. In steps $\mathrm{B}, \mathrm{C}$, and D the influence of the strength of the concrete was varied, ranging from 10 to $150 \mathrm{MPa}$ so as to establish a practical useful upper limit for the concrete strength beyond which no benefit is obtained for the column behavior. It is important to clarify that the numerical concrete model is not calibrated using ultra-high strength concrete, so the conclusions from $110 \mathrm{MPa}$ to $150 \mathrm{MPa}$ should be accepted as an initial tendency. As there are too many variables that influence the behavior of the slender columns under eccentric load, three variables where the main parameters are included were selected on account of their influence on the results of the analyses: confinement index $\theta$ for the section behavior, relative slenderness $\bar{\lambda}$, and the concrete strength $\mathrm{f}_{\mathrm{c}}$.

The confinement index $\theta$ has been employed by various authors and is defined as:

$$
\theta=\frac{A_{s} f_{y}}{A_{c} f_{c}}
$$

This is the ratio between the maximum capacity of steel and concrete, and represents the mechanical slenderness of the section. For short columns this is directly related to the confinement obtained. Other authors call this parameter the mechanical capacity of steel. 
Portolés J1, Romero ML*, Filippou FC and Bonet JL, Simulation and design recommendations of eccentrically loaded slender concrete-filled tubular columns, Engineering Structures 2011: 33 (5), pp. 1576-1593.

The relative slenderness $\bar{\lambda}$ defined in Eurocode 4 is used (instead of L/D) because it includes not only the geometric but also the material properties: $\bar{\lambda}=\sqrt{\frac{N_{p l}}{N_{c r}}}=\sqrt{\frac{A_{c} f_{c}+A_{s} f_{y}}{\frac{\pi^{2} E I}{L^{2}}}}$

where $\mathrm{EI}=\mathrm{E}_{\mathrm{s}} \mathrm{I}_{\mathrm{s}}+0.6 \mathrm{E}_{\mathrm{cm}} \cdot \mathrm{I}_{\mathrm{c}}$

and $I_{s}$ and $I_{c}$ are the second moment of inertia of the steel tube and the concrete core respectively; $\mathrm{E}_{\mathrm{s}}$ is the modulus of elasticity of steel; and $\mathrm{E}_{\mathrm{cm}}$ is the secant modulus of elasticity of concrete.

\section{FAILURE LOAD}

Figure 7 shows the graphs for maximum load in terms of $f_{c}, \theta$ and $\bar{\lambda}$, for sections with an external diameter of $\mathrm{D}=100 \mathrm{~mm}$ and a thickness of 3 and $5 \mathrm{~mm}$ respectively (C100-3, C100-5).

In these graphs, the lines (dashed or continuous) represent the numerical simulation of the parametric study Step A, while the isolated points correspond to the tests, the data of which can be obtained from the table of experiments included in the section 2 . This first parametric study (A) is an extension of the experimental tests (37 cases) with more numerical cases where the strength of concrete varies up to $100 \mathrm{MPa}$ (132 cases).

A satisfactory adjustment is observed between the experiments and the tests as was previously stated.

The general tendency of the curves from Figure 7a) to Figure $7 \mathrm{~b}$ ) is as expected: when the eccentricity or the length is increased the maximum load is reduced. In addition, in these numerical test simulations, when the thickness of the tube or the 
Portolés J1, Romero ML*, Filippou FC and Bonet JL, Simulation and design recommendations of eccentrically loaded slender concrete-filled tubular columns, Engineering Structures 2011: 33 (5), pp. 1576-1593.

strength of the concrete is increased, the load is increased, although this latest increment is lower when high strength concrete is introduced.

It is also interesting to observe that in the cases where there is more eccentricity $(\mathrm{e}=50 \mathrm{~mm})$ and/or length $(\mathrm{L}=3 \mathrm{~m})$, there is only a slight difference between the maximum load from $50 \mathrm{MPa}$ to $100 \mathrm{MPa}$ of concrete, Figure 7a) and b). This seems to indicate that failure is due to the steel tube and that increasing the concrete strength would have barely any effect, so that an expensive HSC might be no more useful than NSC. But since it is not clear whether any value of the strength of the concrete (fc) is reached where the failure load does not increase, an extension to $150 \mathrm{MPa}$ is needed.

From Figures 7a) to d) and with the limitation that only two eccentricities and two lengths are analyzed, it seems that, regardless of the thicknesses, length has a greater influence than eccentricity on the failure load. Only with confinement indexes $(\theta)$ lower than one is there a small increment of $\mathrm{N}_{\max }$. The same conclusion can be reached if the influence of relative slenderness is studied, Figures 7e) and 6f).

To understand these graphs it is important to bear in mind that with the same hollow tube filled with different concretes, the one with higher strength concrete has higher relative slenderness. From these last figures it can be also noted that an increase in eccentricity has a greater effect in the cases of 2 meters (continuous lines) than in the cases of $3 \mathrm{~m}$ (dashed lines). This is because second order effects and imperfections are lower for the shorter columns.

\section{CONCRETE CONTRIBUTION RATIO}

One of the objectives of this paper was to establish the importance of the use of high strength concrete compared with that of normal strength concrete. To do so, the 
Portolés J1, Romero ML*, Filippou FC and Bonet JL, Simulation and design recommendations of eccentrically loaded slender concrete-filled tubular columns, Engineering Structures 2011: 33 (5), pp. 1576-1593.

concrete contribution ratio $(\mathrm{CCR})$ is defined as the ratio between the maximum numerical load ( $\mathrm{N}_{\text {max,num }}$ ) of the composite column and the empty hollow steel member,

$\left(\mathrm{N}_{\max , \text { num, hollow }}\right)$ :

$$
\text { CCR }=\frac{N_{\text {max, num }}}{N_{\text {max, num }, \text { hollow }}}
$$

$\mathrm{N}_{\text {max }}$ num, hollow which is obtained from an identical model but with only steel fibers. There are no effects of local buckling because in all the cases a minimum thickness was required to avoid local buckling in accordance with Eurocodes 3 and 4.

The concrete contribution ratio (CCR) obtained in parametric study $\mathrm{A}$ for the cases with a diameter $\mathrm{D}=100 \mathrm{~mm}$ is presented in Figure 8, while Figure 9 shows the cases with length $\mathrm{L}=3 \mathrm{~m}$ as an alternative.

Although these figures are similar in aspect to those in Figure 7, they contribute more information since they denote the benefits which could be achieved by using concretefilled columns rather than bare steel columns. It can be inferred from these that if the strength of concrete $\left(f_{c}\right)$ increases, the confinement index $(\theta)$ decreases, and the CCR consequently increases. However, this relationship is not linear and tends to a horizontal asymptote for higher values of the strength of concrete. Therefore, the benefits from the use of HSC are reduced drastically.

In addition, if the length of the column (L) or the eccentricity increases, with the $\mathrm{D} / \mathrm{t}$ ratio maintained constant, the CCR is reduced, this reduction being more perceptible for HSC. This statement is in agreement with the observations from the experiments.

Also, for lower ratios of $\mathrm{D} / \mathrm{t}$ (higher thicknesses), enhancement with respect to the hollow steel tube is not as high, Figure 8b). The reason for this is that the concrete core makes less of a mechanical contribution to the composite behavior. It is for this reason 
Portolés J1, Romero ML*, Filippou FC and Bonet JL, Simulation and design recommendations of eccentrically loaded slender concrete-filled tubular columns, Engineering Structures 2011: 33 (5), pp. 1576-1593.

that it is more interesting to observe the response to the mechanical capacity of the steel $(\theta)$ (here called confinement index) than the response to $f_{c}$, taking into account the area of both materials.

From Figure 8c) and d) it can be observed that for values of $\theta<1$ there is a sudden increment of CCR, mostly if eccentricity is smaller.

Again, to understand Figure $8 \mathrm{e}$ ) and f) it is important to bear in mind that if the same hollow tube is filled with different types of concrete, the one with higher strength concrete has higher relative slenderness (if, for instance, we move in the continuous line C100-3-2-fc-20). These give similar information to that in Figure 7e) and f) but focusing on the design recommendations.

Otherwise, if $f_{c}$ is maintained (jumping from one curve to another) and the length is increased, there is almost no difference in the CCR for lower values of $f_{c}$ (lower part of the curves) while for HSC (upper part of the curves) the increments of CCR are higher for $L=2 \mathrm{~m}$ than for $\mathrm{L}=3 \mathrm{~m}$. The same conclusion can be reached if $f_{c}$ is maintained and the eccentricity is incremented

The same can be observed in Figure 8c) and d), because when fc is small (high $\theta$ ), the differences in CCR are smaller, despite the eccentricity or the length of the column. It is obvious that when the column is empty $\left(\theta=\infty, f_{c}=0 \mathrm{MPa}\right) \mathrm{CCR}=1$, there is a horizontal asymptote. In conclusion, it makes sense to design using smaller values for the mechanical capacity of steel.

It can be concluded that a more efficient use of higher strength concrete is obtained when the column is less slender and the load is applied with less relative eccentricity. This conclusion could easily be expected but it is magnified if $\theta$ is lower. 
Portolés J1, Romero ML*, Filippou FC and Bonet JL, Simulation and design recommendations of eccentrically loaded slender concrete-filled tubular columns, Engineering Structures 2011: 33 (5), pp. 1576-1593.

In comparison with previous figures, Figure 9a) to e) present the concrete contribution ratio (CCR) of the cases with $\mathrm{L}=3 \mathrm{~m}$ of the parametric study $\mathrm{A}$, but for all types of section (C100-3, C100-5, C125-5, C160-6).

It can be inferred that if the diameter is maintained but $\mathrm{D} / \mathrm{t}$ is increased, the CCR is increased, which indicates that the contribution of the concrete is higher because of the difference between the composite column and the empty hollow column. However, the effect of increasing the diameter has a greater influence than that of increasing the thickness. Thus, the CCR of the series with a C160-6 section $(\mathrm{D}=160 \mathrm{~mm}$ and $\mathrm{t}=6 \mathrm{~mm}$ ) is higher than the series with the C100-3 section despite the fact that the $\mathrm{D} / \mathrm{t}$ of C160-6 is lower than the $\mathrm{C} 100-3$.

As a design recommendation it could be concluded that to make better use of the HSC and obtain a higher CCR it is more influential to select a lower L/D than a higher $\mathrm{D} / \mathrm{t}$, meaning that the variables which affect the beam-column behavior are more important than the variables that affect the section behavior.

Figure 9 demonstrates the advantage of using greater diameters (lower L/D), as the slope of the CCR is higher and the use of HCS is more interesting.

In addition, parametric studies $\mathrm{B}, \mathrm{C}$, and $\mathrm{D}$ were performed to study the effect of e/D, $\mathrm{L}$, and $\mathrm{D} / \mathrm{t}$ respectively. Figure $10 \mathrm{a}$ ) and $\mathrm{b}$ ) show the evolution of the CCR for relative eccentricities $e / D=0.1,0.2, \ldots, 0.6$ in terms of $f_{c}$. The strength of concrete $\left(f_{c}\right)$ was varied up to $150 \mathrm{MPa}$ and the asymptote was still not achieved, although it seems that it is closer for cases of $\mathrm{C} 100-3$ than for the larger sections (C160-6). In any case, as the increment in the maximum load (or CCR) is small it appears to be more convenient to use medium strength concrete since higher strength concrete is very expensive to use and does not provide any benefits. Again, it is important to remember that the numerical 
Portolés J1, Romero ML*, Filippou FC and Bonet JL, Simulation and design recommendations of eccentrically loaded slender concrete-filled tubular columns, Engineering Structures 2011: 33 (5), pp. 1576-1593.

concrete model from Hajjar and Gourley [52] is not calibrated for strengths of concrete higher than $100 \mathrm{MPa}$, so the conclusions for CCR and SI from $110 \mathrm{MPa}$ to $150 \mathrm{MPa}$ should be approached with caution.

Figure 10a) and b) (variation of the relative eccentricity) and Figure 10 c) and d) (variation of the length) expand upon the results from parametric study A. If the relative eccentricity or the length is increased, the CCR is reduced.

Figure 10a) and c) (on the left) show the evolution for a smaller section $(\mathrm{D}=100$, $t=3)$, and Figure 10b) and d) (on the right) for a bigger section $(D=160, t=5.7)$.

If eccentricity or length are increased, the result is an increase in the total eccentricity in the mid-span section, either an increase of first order eccentricity (e), or an increase in second order eccentricity due to the second order bending moments arising from the displacement of the central section of the column. Clearly, if the section is smaller $(\mathrm{D}=100 \mathrm{~mm})$, second order effects are more important than in the much larger section $(\mathrm{D}=160 \mathrm{~mm})$, because it has a higher geometric slenderness L/D.

It is interesting to notice that for relatively small eccentricities and higher diameters of the columns, the enhancement of the CFT column can be double that of the empty hollow steel column, even using HSC.

In conclusion, if the total eccentricity is great, either first order (e/D) or second order (L/D), the mid-span section is subjected to a higher bending moment. Thus, there is a higher part of the section under tensile forces, so failure occurs early on. A possible solution could be to increase the tension resistance of the section using steel fiber concrete or introducing reinforcements.

The results of parametric study D (variation of D/t) are presented in Figure 11. 
Portolés J1, Romero ML*, Filippou FC and Bonet JL, Simulation and design recommendations of eccentrically loaded slender concrete-filled tubular columns, Engineering Structures 2011: 33 (5), pp. 1576-1593.

This figure presents the CCR for $\mathrm{D} / \mathrm{t}$ ratios between 20 and 50 for two different diameters $(D=100$ and 160$)$ in terms of the mechanical capacity of the steel, $\theta$ (confinement index).

If $\mathrm{D} / \mathrm{t}$ increases (lower thickness), the CCR increases; but for the same $\theta$, the differences are very small. However if $\theta$ is reduced ( $f_{c}$ increases) the differences are higher. Otherwise, it was observed that even though the effect of $\mathrm{D} / \mathrm{t}$ is small, if the diameter is increased the influence of $\mathrm{D} / \mathrm{t}$ increases slightly. It is necessary to study this effect thoroughly since it can be affected by relative slenderness.

In summary, using HSC in combination with $\theta=1$ or lower, the concrete contribution ratio (CCR) will increase. The differences will be more noticeable if e/D is small, $\mathrm{L} / \mathrm{D}$ is small and/or $\mathrm{D} / \mathrm{t}$ is large.

\section{STRENGTH INDEX}

The strength index is defined as:

$$
\mathrm{SI}=\frac{\mathrm{N}_{\max }}{\mathrm{N}_{p l, R d}}=\frac{\mathrm{N}_{\max }}{\mathrm{A}_{\mathrm{c}} \mathrm{f}_{\mathrm{c}}+\mathrm{A}_{\mathrm{s}} \mathrm{f}_{\mathrm{y}}}
$$

It compares the maximum load of the slender column with the resistance of the composite cross section (without any confinement effect). It is similar to the buckling reduction factor $(\chi)$ for a member in axial compression without eccentricity from Eurocode 4, but cannot be linked to any buckling curves. Smaller values of the strength index are not desirable for design.

Figure 12 and Figure 13 show the evolution of the strength index (SI) in terms of the variables $\mathrm{f}_{\mathrm{c}}, \theta, \bar{\lambda}$ for parametric study $\mathrm{A}$. 
Portolés J1, Romero ML*, Filippou FC and Bonet JL, Simulation and design recommendations of eccentrically loaded slender concrete-filled tubular columns, Engineering Structures 2011: 33 (5), pp. 1576-1593.

It can be observed that the SI is reduced when the relative slenderness or the eccentricity is increased.

Comparing Figure 12c) and d), it is seen that the level of SI for the C100-3 and C100-5 sections are very similar for both eccentricities, and may be slightly lower for the greater wall thickness. When all the sections are compared for $\mathrm{L}=3 \mathrm{~m}$, Figure $13 \mathrm{c}$ ) and d), it may be concluded that the sections with larger diameter suffer less resistance reduction in comparison to the resistance of a stub column (high SI). This is an indirect consequence of geometric slenderness $\mathrm{L} / \mathrm{D}$, since if the diameter is higher, both the geometric and the relative slenderness are lower, subsequently the SI increases, Figure 13e) and f). It can also be inferred that the difference between sections with the same diameter $(D=100 \mathrm{~mm})$ and different thickness $(t=3$ or $5 \mathrm{~mm})$ is small. This is because the $\mathrm{D} / \mathrm{t}$ has very little effect on relative slenderness.

Comparing Figure 13a), c) and e) (on the left) $(e=20 \mathrm{~mm})$ with Figure $13 \mathrm{~b}), \mathrm{d})$ and f) (on the right) it can be seen that for higher eccentricities the SI is clearly lower.

It is also shown that below a certain level of mechanical capacity of steel $\theta=1$, the strength index (SI) decreases quickly. If $\theta$ reaches a value of one it indicates that half of the axial resistance under concentric load (and without confinement) comes from the steel, while the other half comes from the concrete.

In complete contrast with the results reached in the previous section, these results show designing with confinement indexes lower than one is not worthwhile.

From Figure 12e) and f) and Figure 13e) and f), where SI is presented in terms of $\lambda$, it can be concluded that the SI parameter is basically influenced by the relative slenderness and eccentricity. The different series are aligned for the same eccentricity, independently (or with a minor influence) from the section. Therefore if the SI is 
Portolés J1, Romero ML*, Filippou FC and Bonet JL, Simulation and design recommendations of eccentrically loaded slender concrete-filled tubular columns, Engineering Structures 2011: 33 (5), pp. 1576-1593.

presented (for all the numerical tests in parametric study A) in terms of $\lambda$, together with European buckling curve a, as in Figure 14, the cases with the same eccentricity create parallel curves. The rest of the cases from parametric studies B, C, and D are in agreement with this result, but are not presented to avoid complication.

\section{DESIGN RECOMMENDATIONS}

Portolés et al. [1] stated (using only the experiments) that the tendency of the CCR is a combination of the relative slenderness $\bar{\lambda}$ (which includes the $f_{c}$ ) and the confinement index, but that more experimental cases or a numerical parametric study were needed to reach a reliable conclusion.

In the previous section two opposing behaviors were observed. The values of $\theta<1$ reduce the strength index SI drastically, while the best CCR values are achieved for $\theta$ $<1$.

One way to establish the optimum $\theta$ is by using the product of both parameters CCR*SI. Figure 15 shows the effect of $\theta$ on this product for parametric studies $B$ (variation of e/D), C (variation of $\mathrm{L}$ ), and $\mathrm{D}$ (variation of $\mathrm{D} / \mathrm{t}$ ). The general response is that a maximum is reached for values of $\theta$ lower than one. The exact value of the maximum depends on the eccentricity and the geometric slenderness, which will be more pronounced for small eccentricities and smaller lengths. If the length or eccentricity is high, the product $\mathrm{CCR}^{*} \mathrm{SI}$ is almost constant for larger values of $\theta$, and is reduced quickly for $\theta<1$ (for all cases).

In addition, an increase in $\mathrm{D} / \mathrm{t}$ (lower thickness) increases the product $\mathrm{CCR} * \mathrm{SI}$, signaling that there is a particular value of $\mathrm{D} / \mathrm{t}$ which maximizes it, providing that $\theta<1$, as in Figure 15d) and e). 
Portolés J1, Romero ML*, Filippou FC and Bonet JL, Simulation and design recommendations of eccentrically loaded slender concrete-filled tubular columns, Engineering Structures 2011: 33 (5) , pp. 1576-1593.

The results show that for slender elements the optimum design (with respect to the contribution of the concrete) is achieved when the mechanical capacity of the steel is slightly lower than the mechanical capacity of the concrete contribution $(\theta \approx 1)$.

As the typical data in the practical design are the length (L), axial load $\left(\mathrm{N}_{\mathrm{d}}\right)$, bending moment $\left(\mathrm{M}_{\mathrm{d}}\right)$ and fy, the following steps could be followed to pre-design the columns:

- Calculate the first order eccentricity e $=\mathrm{M}_{\mathrm{d}} / \mathrm{N}_{\mathrm{d}}$.

- Obtain the diameter of steel necessary to resist half the axial load $\left(\mathrm{N}_{\mathrm{d}} / 2\right)$ using the lower thickness of a series $(\mathrm{t})$ which avoids local buckling. The diameter must be the maximum allowed by architectural requirements.

- If e/D is large, increase the diameter and correct the thickness.

- Obtain the corresponding fc to obtain the rest of the axial resistance $\left(\mathrm{N}_{\mathrm{d}} / 2\right)$.

\section{CONCLUSIONS}

In this paper an efficient numerical model was calibrated in order to perform an extended parametric study. It has been developed in order to propose some design recommendations, whose main objectives are to establish the importance of the use of high strength concrete.

An existing beam finite element model with geometric nonlinearity for the simulation of the nonlinear buckling behavior of slender circular CFT column was validated. The model was applied to high strength columns with medium and high eccentricities.

To represent the second order effects along the column length this was subdivided into four elements and the co-rotational formulation was used for the transformation of the nodal variables. A section discretization with 2 fibers for the steel tube and 8 fibers for the concrete in the radial direction, with 16 fibers in the circumferential direction 
Portolés J1, Romero ML*, Filippou FC and Bonet JL, Simulation and design recommendations of eccentrically loaded slender concrete-filled tubular columns, Engineering Structures 2011: 33 (5), pp. 1576-1593.

provided highly accurate results. Despite the lack of a large number of fibers the model proved to be very efficient computationally because of the uniaxial stress-strain relation used for the constituent materials. Furthermore, it proved numerically robust.

The validation of the model against the available experimental data shows that the increase in concrete strength due to confinement by the tube is negligible for slender columns with medium to high eccentricity of the applied axial load. The confinement plays an important role for the descending post-peak behavior of the columns. This effect is captured well by the uniaxial confined concrete model of Hajjar and Gourley [52].

The initial imperfection of the slender column plays an important role when determining the buckling load. The correlation studies show that a sine wave with maximum eccentricity of $\mathrm{L} / 600$ produces the best match.

This model is therefore an ideal tool for conducting parametric studies to derive design recommendations for slender circular CFT columns.

This paper focuses on studying the influence the variables which affect the beamcolumn behavior and the variables which affect the section behavior have on global buckling behavior in this type of column.

The results show that for slender elements the optimum design (with respect to the contribution of the concrete) is reached when the mechanical capacity of the steel is slightly lower than the mechanical capacity of the concrete contribution.

As a design recommendation, it could be concluded that to make better use of the HSC and get a higher CCR it is more effective to select lower L/D and lower e/D than higher $\mathrm{D} / \mathrm{t}$, which means that the variables that affect the beam-column behavior are more important than the variables that affect the section behavior. 
Portolés J1, Romero ML*, Filippou FC and Bonet JL, Simulation and design recommendations of eccentrically loaded slender concrete-filled tubular columns, Engineering Structures 2011: 33 (5), pp. 1576-1593.

It appears to be more suitable to use medium strength concrete since higher strength is very expensive to use and does not provide sufficient benefits.

Further work should be carried out to study possible solutions for increasing the tension resistance of the section using steel fiber concrete or reinforcement bars.

In summary, when employing HSC in combination with $\theta=1$ or slightly lower, the concrete contribution ratio (CCR) will increase. The differences will be more noticeable if $\mathrm{e} / \mathrm{D}$ is small, $\mathrm{L} / \mathrm{D}$ is small and/or $\mathrm{D} / \mathrm{t}$ is large.

\section{ACKNOWLEDGEMENTS}

The authors wish to express their sincere gratitude to the Spanish "Ministerio de Educación" for help provided with project BIA2005_255, and to the Spanish “Ministerio de Ciencia e Innovación" with project BIA2009-09411, to the European Community for FEDER funds, and to the Fundació Caixa Castelló- Bancaixa.

\section{REFERENCES}

[1] Portolés J.M., Romero M.L., Bonet J.L. and Filippou F.C., Experimental study of high strength concrete-filled circular tubular columns under eccentric loading, Journal of Constructional Steel Research 2010; 67:623-633.

[2] European Committee of Standardization. EN 1994-1-1:2004 Eurocode 4: Design of composite steel and concrete structures Part 1-1: General rules and rules for buildings. 2004.

[3] Johansson M., Gylltoft K. Structural behaviour of slender circular steel- concrete composite columns under various means of load application. Steel and Composite Structures 2001; 1(4):393-410.

[4] Johansson, M. Composite Action and Confinement Effects in Tubular SteelConcrete Columns. Department of Structural Engineering, Chalmers University of Technology, Doctoral Thesis, Publication 02:8, Göteborg, Sweden, November 2002, 173 pp.

[5] Zeghiche J, Chaoui K. An experimental behaviour of concrete-filled steel tubular columns. J Construct Steel Res 2005; 61(1): 53-66.

[6] O'Shea MD, Bridge RQ. Design of circular thin-walled concrete filled steel tubes. J Struct Eng 2000; 126(11):1295-1303. 
Portolés Jl, Romero ML*, Filippou FC and Bonet JL, Simulation and design recommendations of eccentrically loaded slender concrete-filled tubular columns, Engineering Structures 2011: 33 (5), pp. 1576-1593.

[7] Han L.H., Tests on concrete filled steel tubular columns with high slenderness ratio, Advances in Structural Engineering 2000; 3(4): 337-344.

[8] Sakino K, Nakahara H, Morino S, Nishiyama A, Behavior of centrally loaded concrete-filled steel-tube short columns, Journal of Structural Engineering-ASCE 2004; 130(2): 180-188.

[9] Fujimoto T, Mukai A, Nishiyama I. Behavior of eccentrically loaded concretefilled steel tubular columns, Journal of Structural Engineering-ASCE 2004; 130(2): 203-212.

[10] Grauers M. Composite columns of hollow sections filled with high strength concrete. Research report. Chalmers University of Technology, Göteborg, 1993.

[11] Bergmann, R. Load introduction in composite columns filled with high strength concrete, Proceedings of the 6th International Symposium on Tubular Structures, Monash University, Melbourne, Australia, 1994.

[12] Varma AH, Ricles JM, Sause R, Lu L-W. Experimental behaviour of high strength square concrete-filled steel tube beam-columns. J Struct Eng ASCE 2002; 128(3):309-327.

[13] Spacone E, El-Tawil S, Nonlinear analysis of steel-concrete composite structures: State of the art, Journal of Structural Engineering-ASCE 2004; 130 (2): 159-168.

[14] Hajjar, J. F.; Gourley, B. C., A Cyclic Nonlinear Model for Concrete-Filled Tubes, Formulation, Journal of Structural Engineering-ASCE 1997; 123(6):736744.

[15] M.L. Romero, J.L. Bonet, S. Ivorra, "A Review of Nonlinear Analysis Models for Concrete Filled Tubular Columns", in B.H.V. Topping, (Editor), "Innovation in Civil and Structural Engineering Computing", Saxe-Coburg Publications, Stirlingshire, UK, Chapter 6, pp 119-142, 2005. doi:10.4203/csets.13.6.

[16] De Sousa JBM, Caldas RB, Numerical analysis of composite steel-concrete columns of arbitrary cross section, Journal of Structural Engineering-ASCE 2005;131(11): 1721-1730.

[17] Hajjar, J. F., Schiller, P. H., and Molodan, A. A Distributed Plasticity Model for Concrete-Filled Steel Tube Beam-Columns with Interlayer Slip, Engineering Structures 1998; 20(8): 663-676.

[18] Spacone E, Filippou F, Taucer F. Fibre beam-column model for non-linear analysis of R/C frames. Part 1. Formulation. Earthquake Engineering \& Structural Dynamics 1996; 25(7):711-725.

[19] Neuenhofer A, Filippou FC, Geometrically nonlinear flexibility-based frame finite element, Journal of structural engineering-ASCE 1998; 124 (6): 704-711.

[20] De Souza, R. M., "Force-Based Finite Element for Large Displacement Inelastic Analysis of Frames", Ph.D. Dissertation, University of California at Berkeley, Berkeley, CA, 2000.

[21] Valipour H, Foster S. Nonlinear static and cyclic analysis of concrete-filled steel columns. Journal of Constructional Steel Research 2010; 66(6):793-802.

[22] Ayoub A, Filippou F. Mixed formulation of nonlinear steel-concrete composite beam element. Journal of structural engineering 2000; 126(3):371-381.

[23] Limkatanyu S, Spacone E. Reinforced concrete frame element with bond interfaces. I: Displacement-based, force-based, and mixed formulations. Journal of structural engineering-ASCE 2002; 128(3):346-355. 
Portolés Jl, Romero ML*, Filippou FC and Bonet JL, Simulation and design recommendations of eccentrically loaded slender concrete-filled tubular columns, Engineering Structures 2011: 33 (5) , pp. 1576-1593.

[24] Spacone E, Ciampi V, Filippou FC., Mixed formulation of nonlinear beam finiteelement, Computers \& Structures 1996; 58(1):71-83.

[25] Taylor R, Filippou F, Saritas A, Auricchio F., Mixed finite element method for beam and frame problems. Computational mechanics 2003; 31(1-2):192-203.

[26] Pi YL, Bradford MA, Uy B. Second order nonlinear inelastic analysis of composite steel-concrete members. I: Theory, Journal of Structural EngineeringASCE 2006; 132 (5): 751-761.

[27] Tort C, Hajjar J. Mixed Finite-Element Modeling of Rectangular Concrete-Filled Steel Tube Members and Frames under Static and Dynamic Loads. Journal of structural engineering 2010;136(6):654-664.

[28] S. Mazzoni, F. McKenna, M.H. Scott, and G.L. Fenves, Open System for Earthquake Engineering Simulation. User Command-Language Manual, Berkeley, CA: Pacific Earthquake Engineering Research Center. University of California, Berkeley, 2009.

[29] F. Filippou and M. Constantinides, FEDEASLab. Getting Started Guide and Simulation Examples. Technical Report NEESgrid-2004-22, Berkeley, CA: Civil and Environmental Eng. Dept. University of California at Berkeley, 2004.

[30] Gourley, B. C., Tort, C., Denavit, M. D., Schiller, P. H., and Hajjar, J. F. A Synopsis of Studies of the Monotonic and Cyclic Behavior of Concrete-Filled Steel Tube Beam-Columns, Report No. UILU-ENG-2008-1802, Newmark Structural Laboratory Report Series (ISSN 1940-9826), Department of Civil and Environmental Engineering, University of Illinois at Urbana-Champaign, Urbana, Illinois, April. 2008.

[31] European Committee of Standardization. EN 1994-1-1:2004 Eurocode 4: Design of composite steel and concrete structures Part 1-1: General rules and rules for buildings. 2004.

[32] Scott M, Franchin P, Fenves G, Filippou F. Response sensitivity for nonlinear beam-column elements. Journal of structural engineering 2004; 130(9):12811288.

[33] M.L. Romero, J.L. Bonet, S. Ivorra, A. Hospitaler, "A Numerical Study of Concrete Filled Tubular Columns with High Strength Concrete", in B.H.V. Topping, (Editor), "Proceedings of the Tenth International Conference on Civil, Structural and Environmental Engineering Computing", Civil-Comp Press, Stirlingshire, UK, Paper 45, 2005. doi:10.4203/ccp.81.45.

[34] Zeghiche J, Chaoui K, An experimental behaviour of concrete-filled steel tubular columns, Journal Of Constructional Steel Research 2005; 61 (1): 53-66.

[35] Rangan BV, Joyce M, Strength Of Eccentrically Loaded Slender Steel Tubular Columns Filled With High-Strength Concrete, ACI STRUCT J 1992; 89 (6): 676681 .

[36] Neogi, P.K.,Sen, H.K., Chapman J.C., Concrete-Filled Tubular Steel Columns under Eccentric Loading, Structural Engineer 1969; 47(5):187-195.

[37] Kilpatrick AE, Rangan BV, Influence of interfacial shear transfer on behavior of concrete-filled steel tubular columns, ACI STRUCT J 1999; 96 (4): 642-648.

[38] M. Menegotto and P.E. Pinto, "Method of analysis for cyclically loaded R.C. plane frames including changes in geometry and non-elastic behavior of elements under combined normal force and bending", Proc-, IABSE. Symposium on 
Portolés Jl, Romero ML*, Filippou FC and Bonet JL, Simulation and design recommendations of eccentrically loaded slender concrete-filled tubular columns, Engineering Structures 2011: 33 (5), pp. 1576-1593.

Resistance and Ultimate Deformability of Structures Acted on by Well Defined Repeated Load, Lisbon: 1973.

[39] M. Tomii and K. Sakino, Elastoplastic behavior of concrete filled square steel tubular beam-columns, Transactions of the Architectural Institute of Japan. 1979; 111-122.

[40] Shams M, Saadeghvaziri M. Nonlinear response of concrete-filled steel tubular columns under axial loading. ACI structural journal 1999; 96(6):1009-1017.

[41] Susantha K, Ge H, Usami T. Uniaxial stress-strain relationship of concrete confined by various shaped steel tubes. Engineering structures 2001; 23(10):13311347.

[42] Hatzigeorgiou, G.D. Numerical model for the behavior and capacity of circular CFT columns, Part I: Theory. Engineering structures 2008; 30 (6): 1573-1578.

[43] Xiao Y, He W, Choi K. Confined concrete-filled tubular columns. Journal of structural engineering 2005; 131(3):488-497.

[44] $\mathrm{Hu} \mathrm{H}$, Huang $\mathrm{C}, \mathrm{Wu} \mathrm{M}, \mathrm{Wu} \mathrm{Y}$. Nonlinear analysis of axially loaded concretefilled tube columns with confinement effect. Journal of structural engineeringASCE 2003; 129(10):1322-1329.

[45] F. Richart, A. Brandtzæg, and R. Brown, A study of the failure of concrete under combined compressive stresses, Bull 185, University of Illinois at Urbana Champaign, College of Engineering. Engineering Experiment Station., 1928.

[46] Nakahara H, Sakino K, Inai E. Analytical Model for Compressive Behavior of Concrete Filled Square Steel Tubular Columns. Transactions of the Japan Concrete Institute 1998; 20:171-178.

[47] Uy B. Strength of Concrete Filled Steel Box Columns Incorporating Local Buckling. Journal of Structural Engineering-ASCE 2000; 126(3): 341-352.

[48] Hatzigeorgiou, G.D. Numerical model for the behavior and capacity of circular CFT columns, Part II: Verification and extension. Engineering structures 2008; 30 (6): 1579-1589.

[49] Liang QQ. Nonlinear analysis of short concrete-filled steel tubular beam-columns under axial load and biaxial bending. Journal of Constructional Steel Research 2008; 64(3):295-304.

[50] $\mathrm{Hu} \mathrm{H}$, Huang C, Chen Z. Finite element analysis of CFT columns subjected to an axial compressive force and bending moment in combination. Journal of Constructional Steel Research 2005; 61(12):1692-1712.

[51] Liang QQ, Fragomeni S, Nonlinear analysis of circular concrete-filled steel tubular short columns under eccentric loading, Journal of Constructional Steel Research 2010; 66(2): 159-169.

[52] Hajjar, J., and Gourley. B. Representation of concrete-filled steel tube crosssection strength. Journal of Structural Engineering-ASCE 1996; 122 (11): 13271336.

[53] Liang QQ, Strength and ductility of high strength concrete-filled steel tubular beam-columns. Journal of Constructional Steel Research 2009; 65(3):687-698.

[54] Varma A, Sause R, Ricles J, Li Q. 2005. Development and validation of fiber model for high-strength square concrete-filled steel tube beam-columns. ACI structural journal 102(1):73-84.

[55] M. Collins, D. Mitchell, and J. MacGregor, Structural Design Considerations for High-Strength Concrete, Concrete International 1993; 15:27-34. 
Portolés J1, Romero ML*, Filippou FC and Bonet JL, Simulation and design recommendations of eccentrically loaded slender concrete-filled tubular columns, Engineering Structures 2011: 33 (5) , pp. 1576-1593.

[56] Romero M, Miguel P, Cano J. A parallel procedure for nonlinear analysis of reinforced concrete three-dimensional frames. Computers \& Structures 2002; 80(16-17):1337-1350.

[57] Bonet J, Romero M, Miguel P, Fernandez M. A fast stress integration algorithm for reinforced concrete sections with axial loads and biaxial bending. Computers \& structures 2004; 82(2-3):213-225.

[58] Comité Euro-international du Béton and Fédération Internationale de la Précontrainte, CEB-FIP model code 1990, T. Telford, 1993.

[59] T.V. Galambos and A.E. Surovek, Structural stability of steel, John Wiley and Sons, 2008. 
Portolés J1, Romero ML*, Filippou FC and Bonet JL, Simulation and design recommendations of eccentrically loaded slender concrete-filled tubular columns, Engineering Structures 2011: 33 (5), pp. 1576-1593.

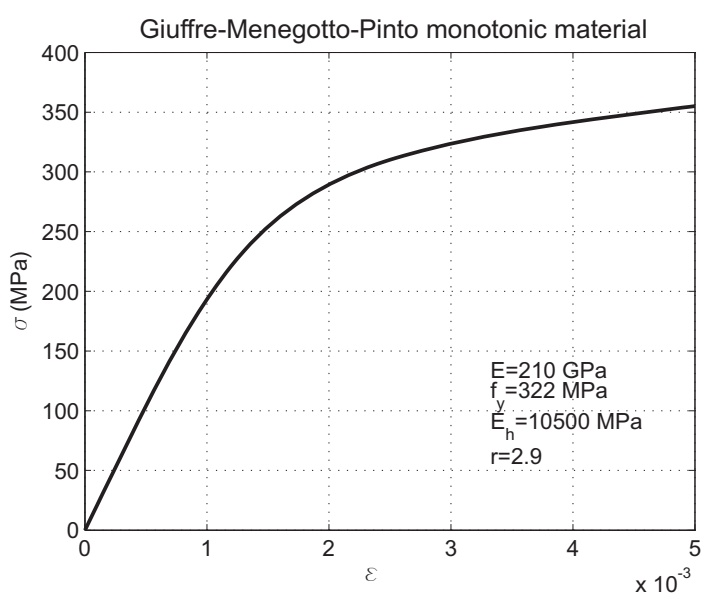

a)

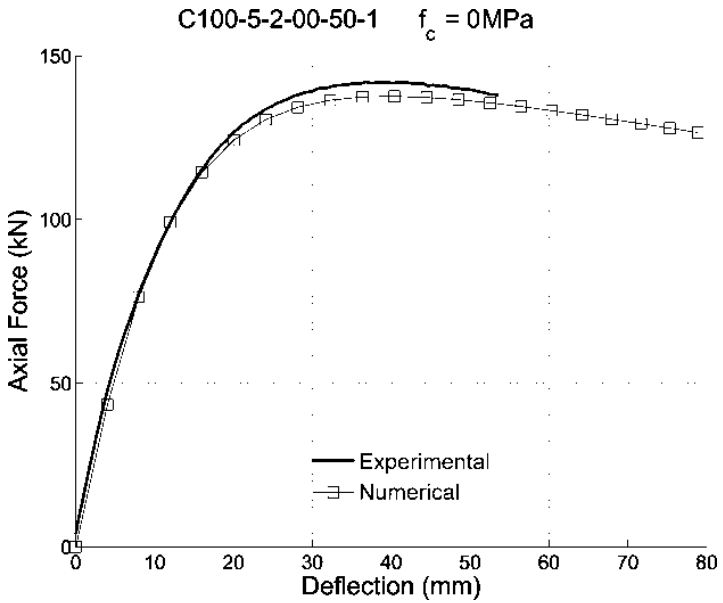

b)

Figure 1. Steel model a) Giuffre-Menegotto-Pinto model b) Force-displacement response of the hollow column test C100-5-2-00-50. 
Portolés J1, Romero ML*, Filippou FC and Bonet JL, Simulation and design recommendations of eccentrically loaded slender concrete-filled tubular columns, Engineering Structures 2011: 33 (5) , pp. 1576-1593.

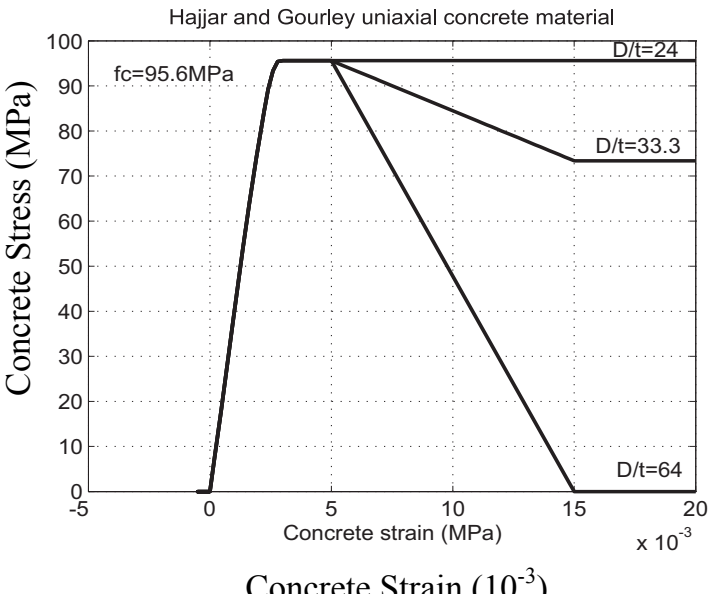

Concrete Strain $\left(10^{-3}\right)$

a)

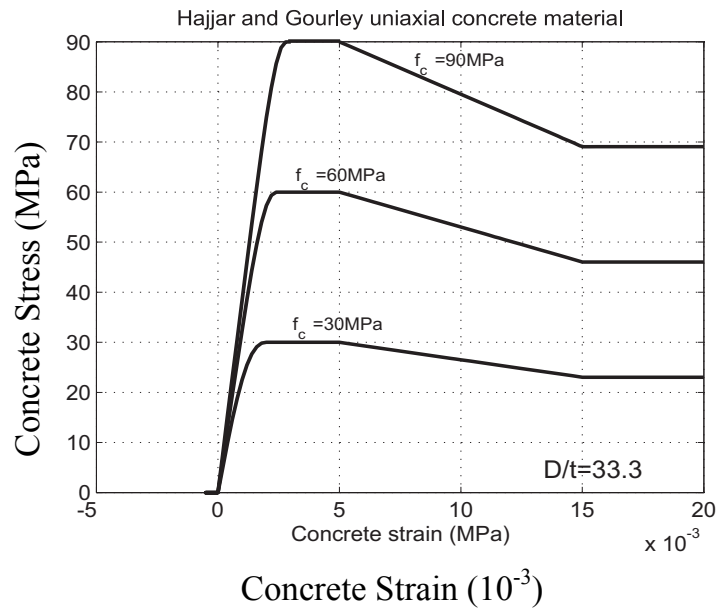

b)

Figure 2. Hajjar and Gourley [52] concrete model a) for different $\mathrm{D} / \mathrm{t}$ ratios b) for different strengths of concrete. 
Portolés J1, Romero ML*, Filippou FC and Bonet JL, Simulation and design recommendations of eccentrically loaded slender concrete-filled tubular columns, Engineering Structures 2011: 33 (5), pp. 1576-1593.

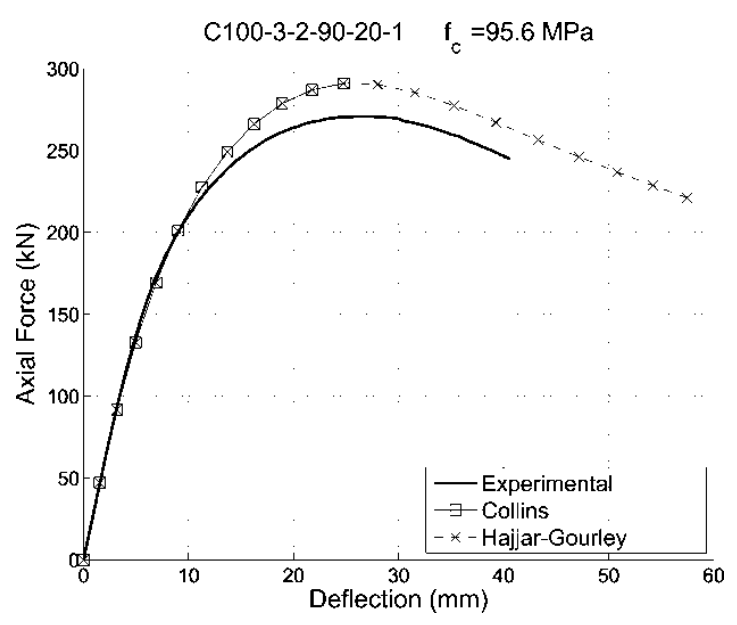

Figure 3. Comparison of concrete model. 
Portolés J1, Romero ML*, Filippou FC and Bonet JL, Simulation and design recommendations of eccentrically loaded slender concrete-filled tubular columns, Engineering Structures 2011: 33 (5), pp. 1576-1593.
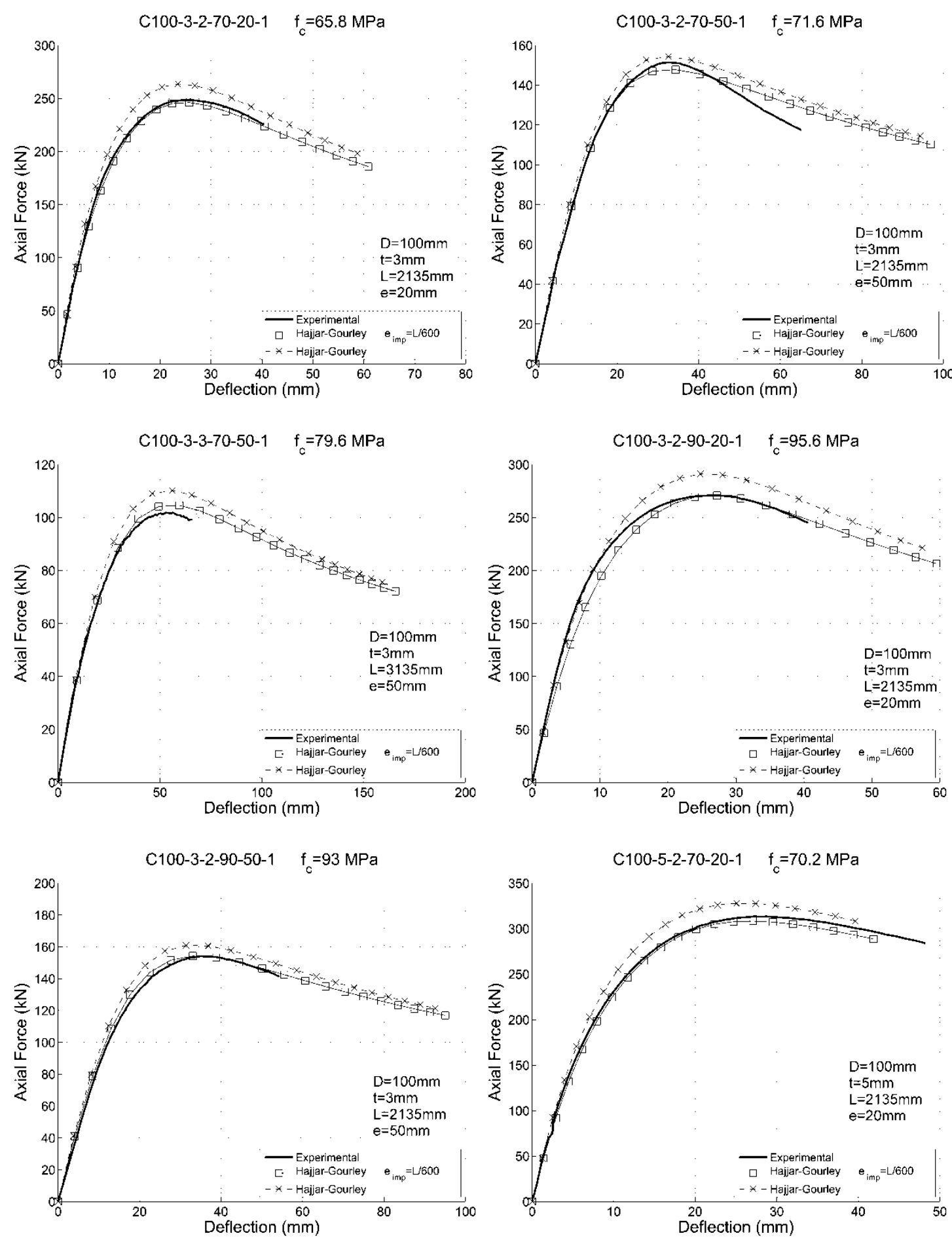

Figure 4. Force-displacement comparison of some experiments and numerical model. 
Portolés J1, Romero ML*, Filippou FC and Bonet JL, Simulation and design recommendations of eccentrically loaded slender concrete-filled tubular columns, Engineering Structures 2011: 33 (5), pp. 1576-1593.

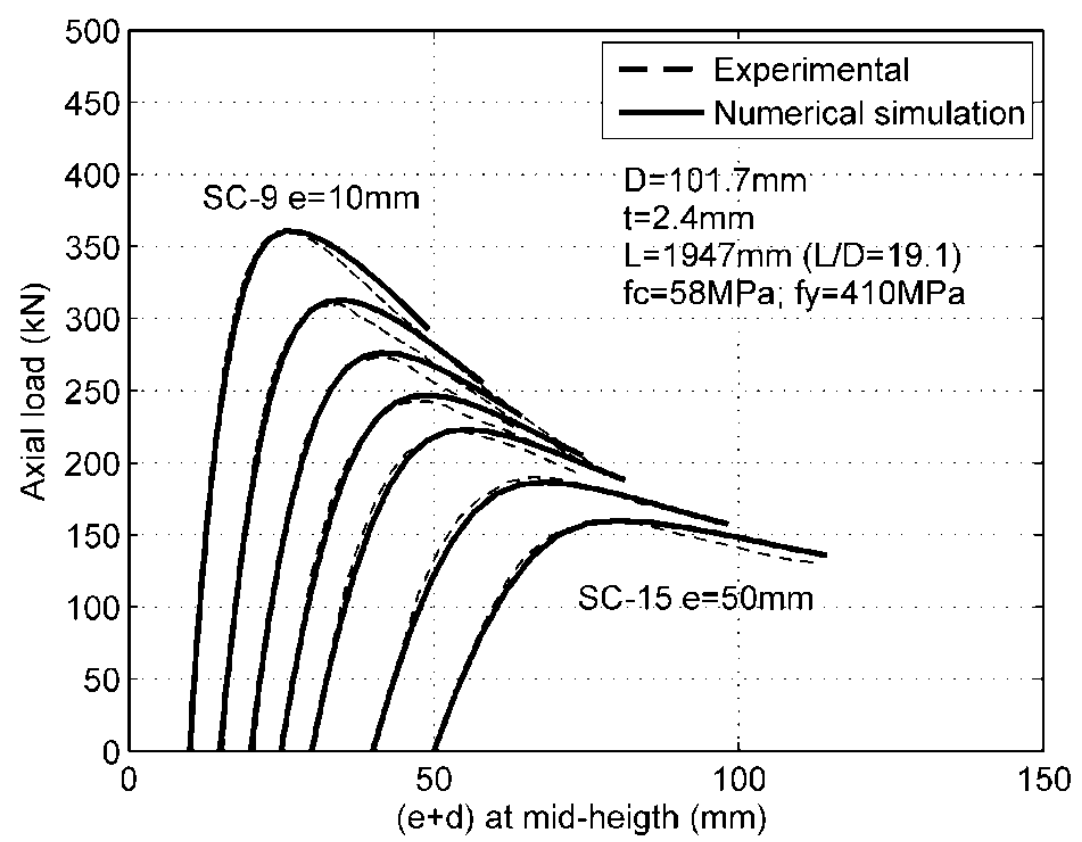

Figure 5. Force-displacement comparison of the experiments and numerical model from Kilpatrick and Rangan [37]. 
Portolés Jl, Romero ML*, Filippou FC and Bonet JL, Simulation and design recommendations of eccentrically loaded slender concrete-filled tubular columns, Engineering Structures 2011: 33 (5) , pp. 1576-1593.

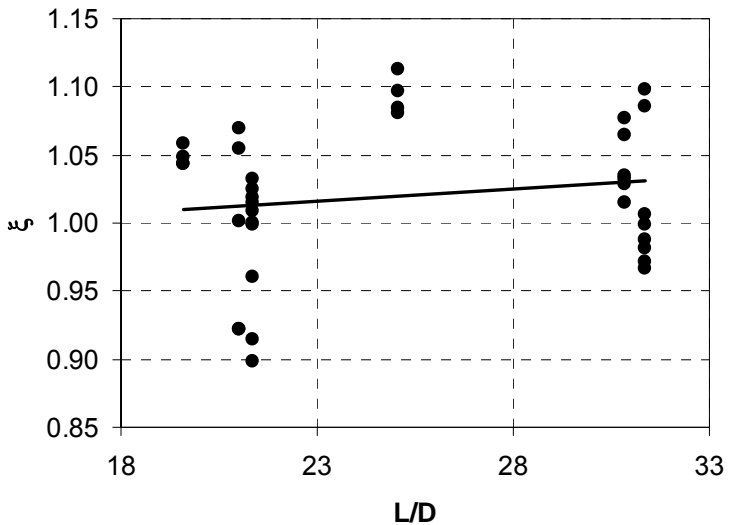

(a)

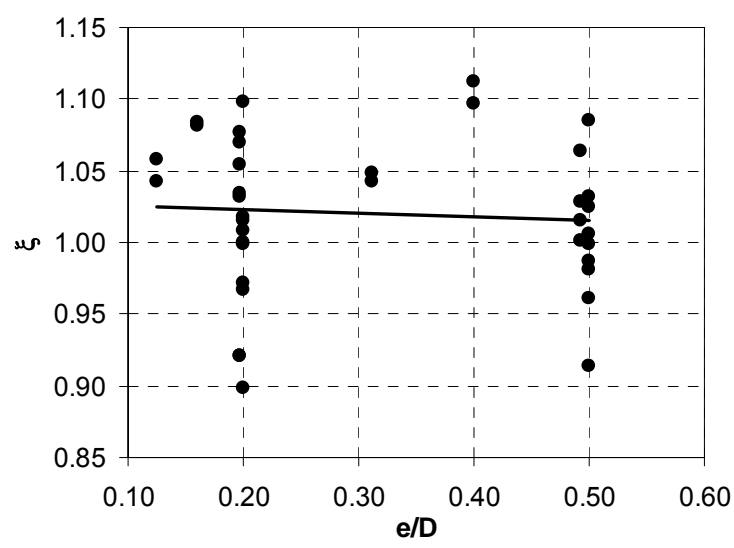

(c)

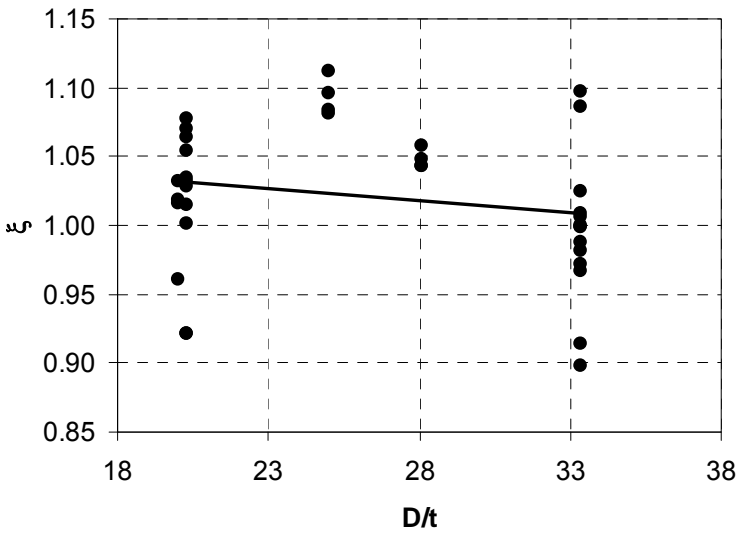

(b)

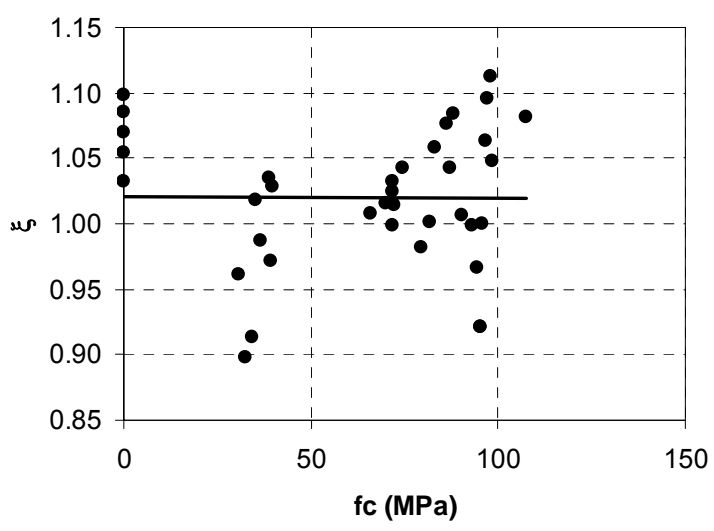

(d)

Figure 6. Scatter in terms of: a) Geometric Slenderness L/D, b) Diameter to thickness ratio D/t, c) Relative eccentricity e/D, d) Strength of concrete fc (MPa). 
Portolés Jl, Romero ML*, Filippou FC and Bonet JL, Simulation and design recommendations of eccentrically loaded slender concrete-filled tubular columns, Engineering Structures 2011: 33 (5), pp. 1576-1593.

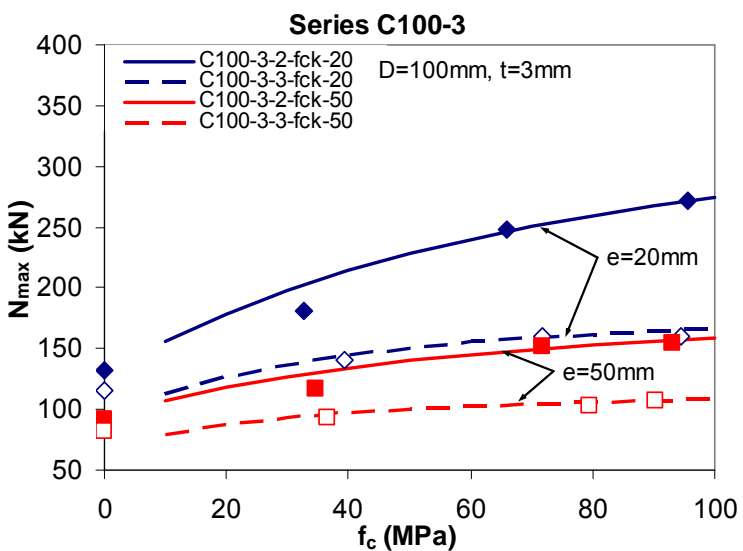

a)

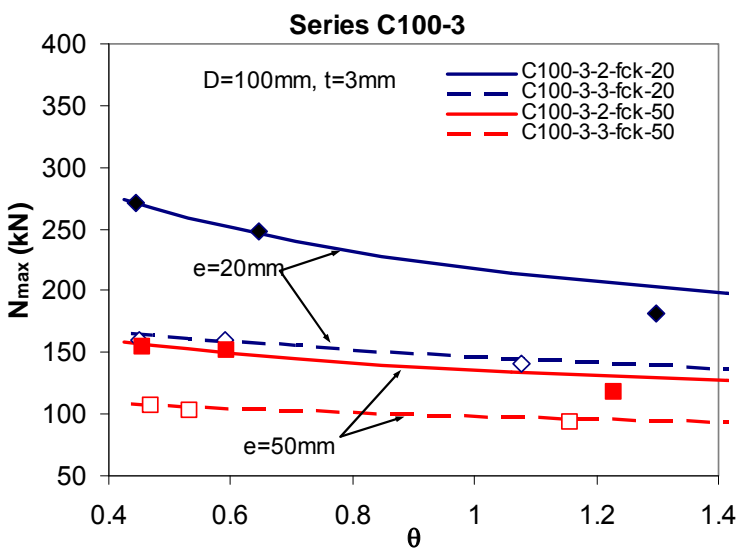

c)

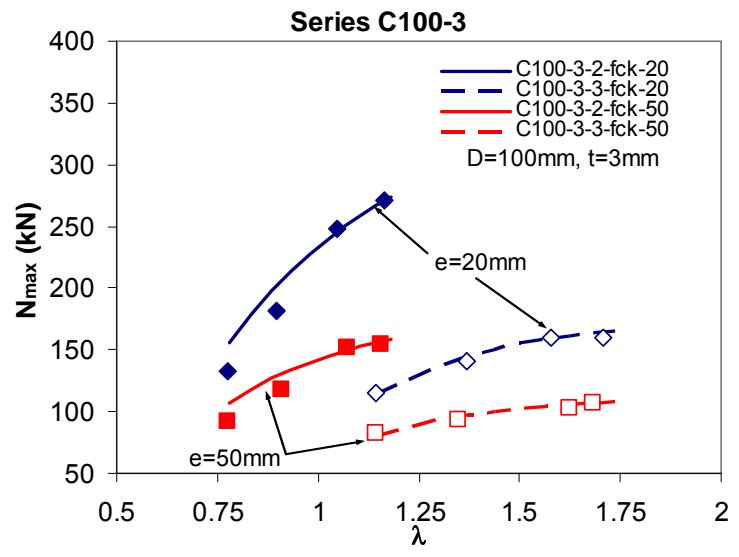

e)

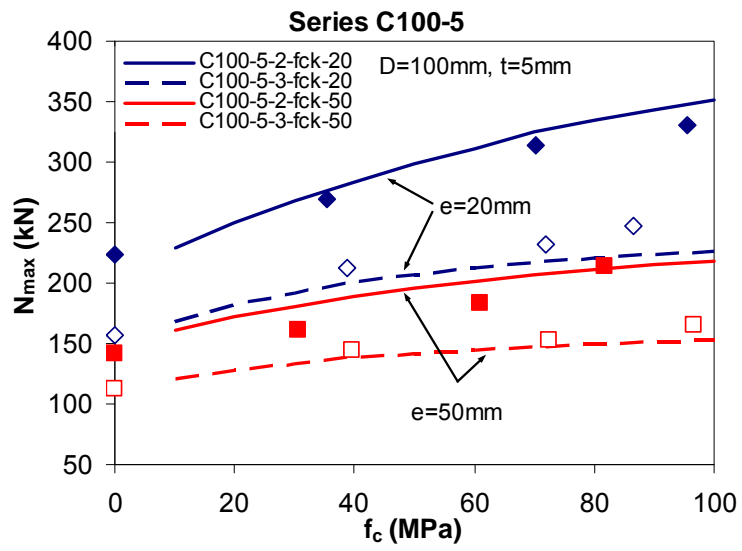

b)

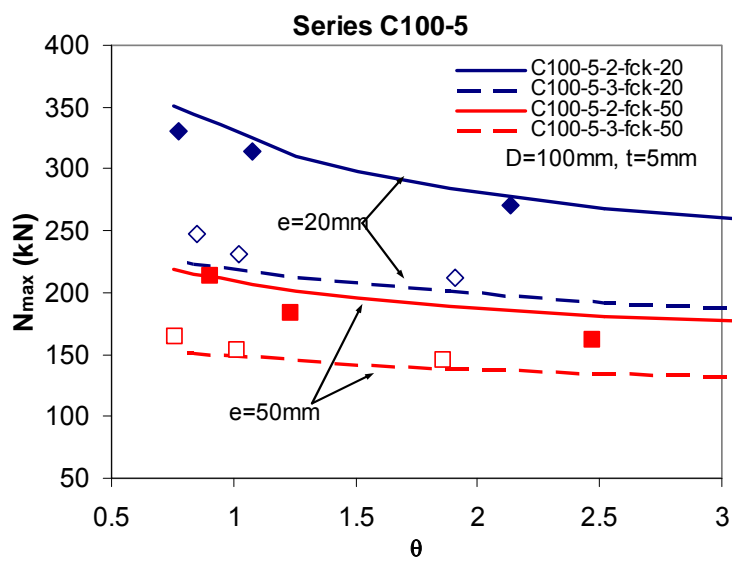

d)

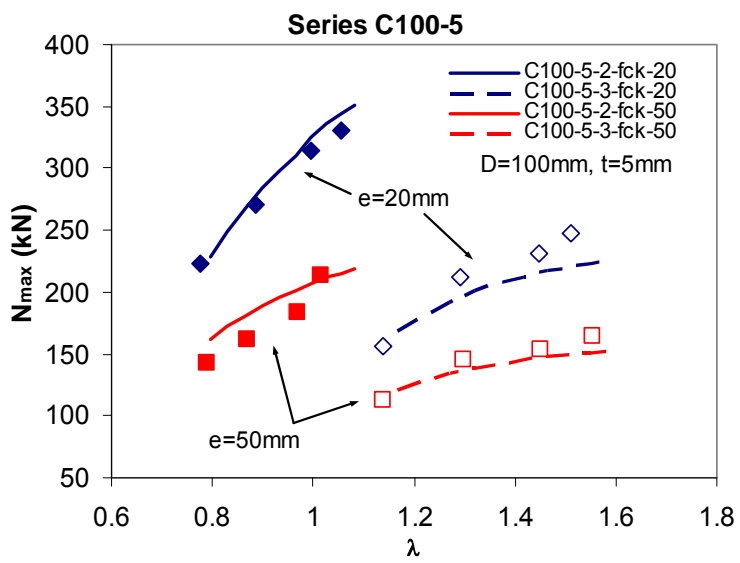

f)

Figure 7. Failure loads from the cases in parametric study "Step A". 
Portolés J1, Romero ML*, Filippou FC and Bonet JL, Simulation and design recommendations of eccentrically loaded slender concrete-filled tubular columns, Engineering Structures 2011: 33 (5), pp. 1576-1593. 
Portolés Jl, Romero ML*, Filippou FC and Bonet JL, Simulation and design recommendations of eccentrically loaded slender concrete-filled tubular columns, Engineering Structures 2011: 33 (5), pp. 1576-1593.

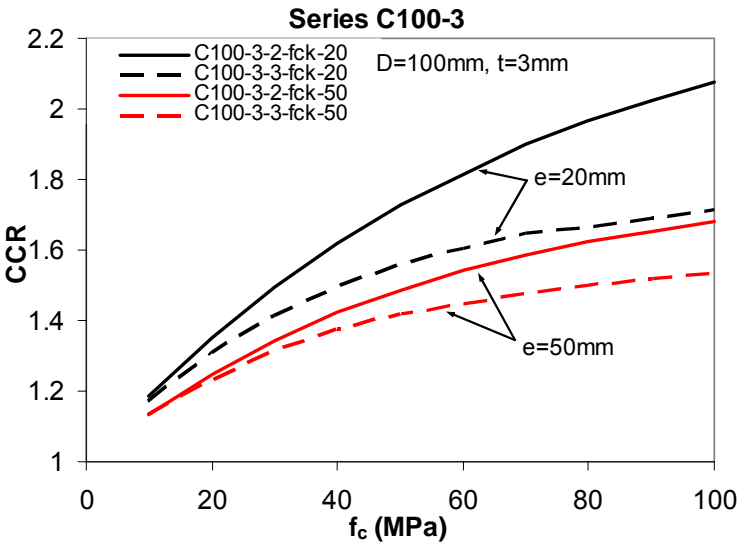

a)

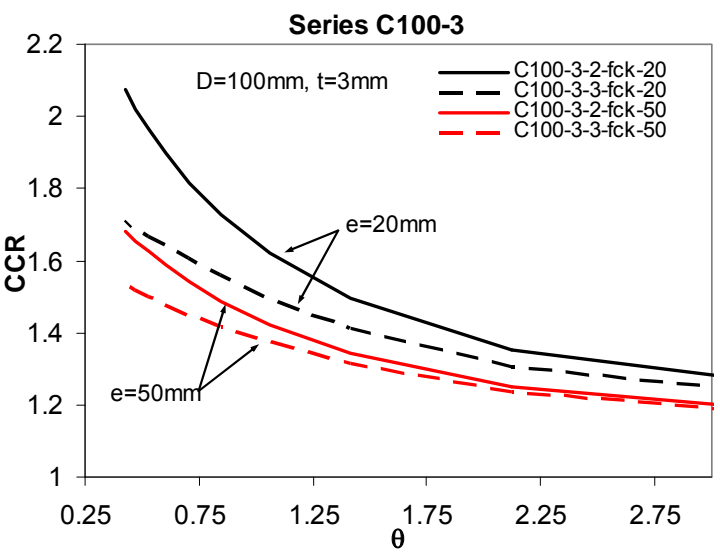

c)

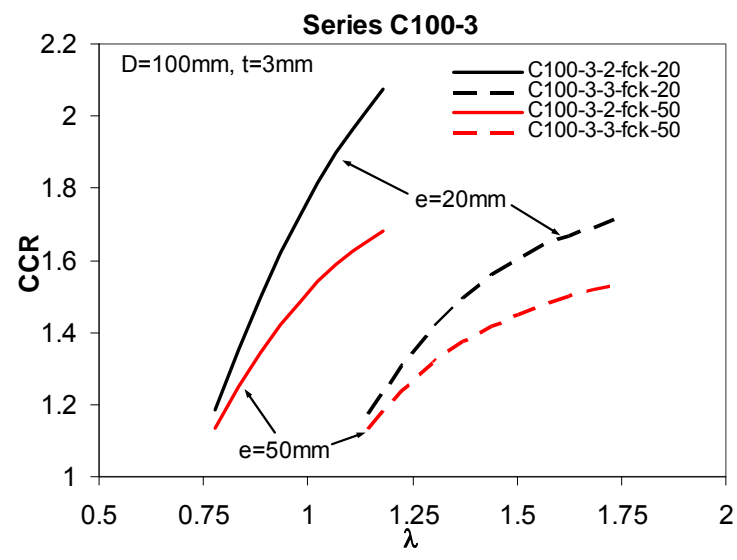

e)

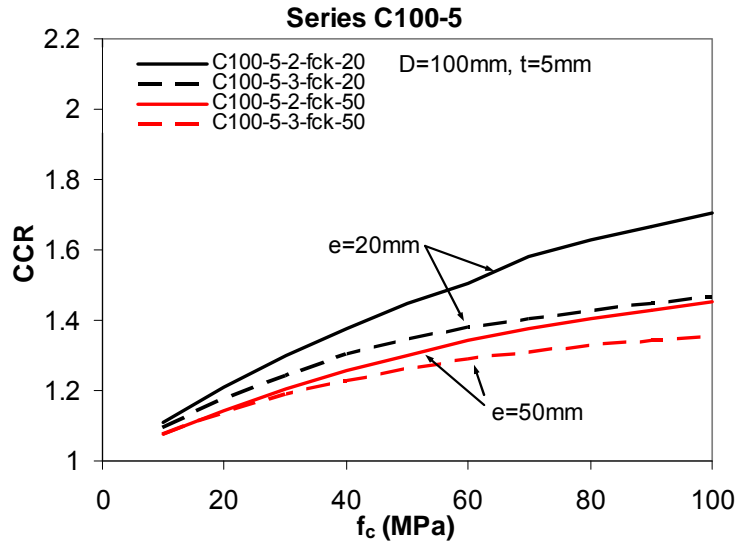

b)

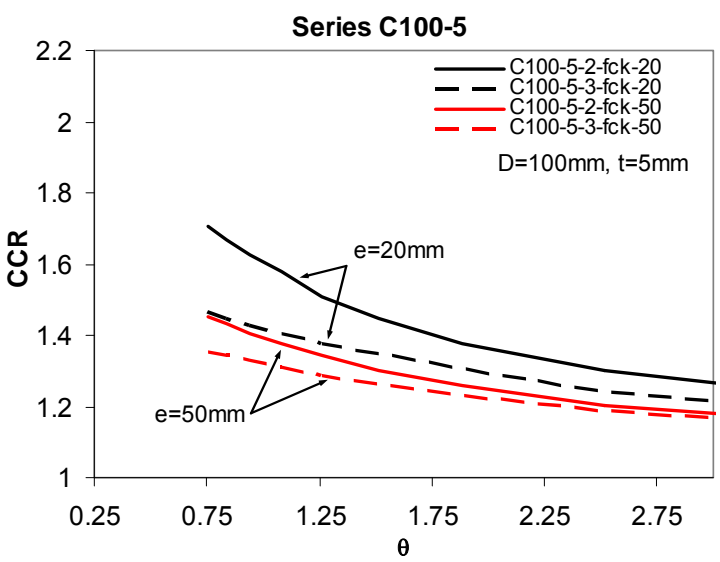

d)

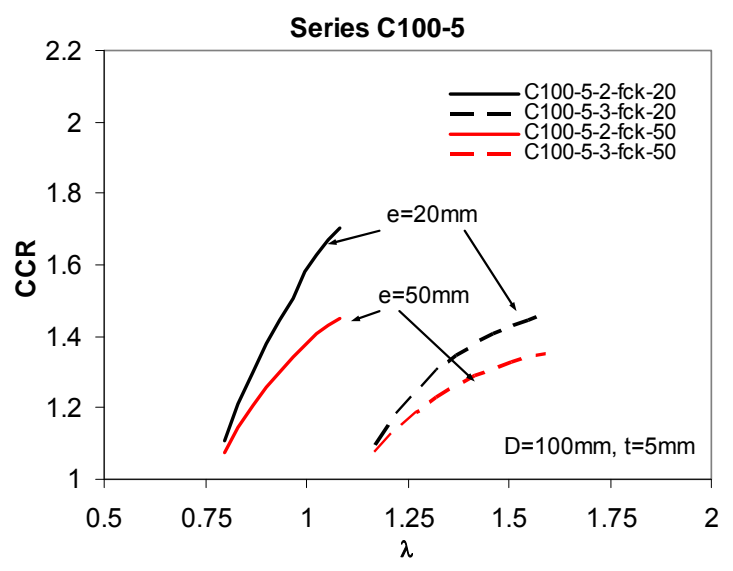

f)

Figure 8. Concrete contribution ratio (CCR) in the cases with $\mathrm{D}=100 \mathrm{~mm}$ in parametric study "Step A". 
Portolés Jl, Romero ML*, Filippou FC and Bonet JL, Simulation and design recommendations of eccentrically loaded slender concrete-filled tubular columns, Engineering Structures 2011: 33 (5), pp. 1576-1593.

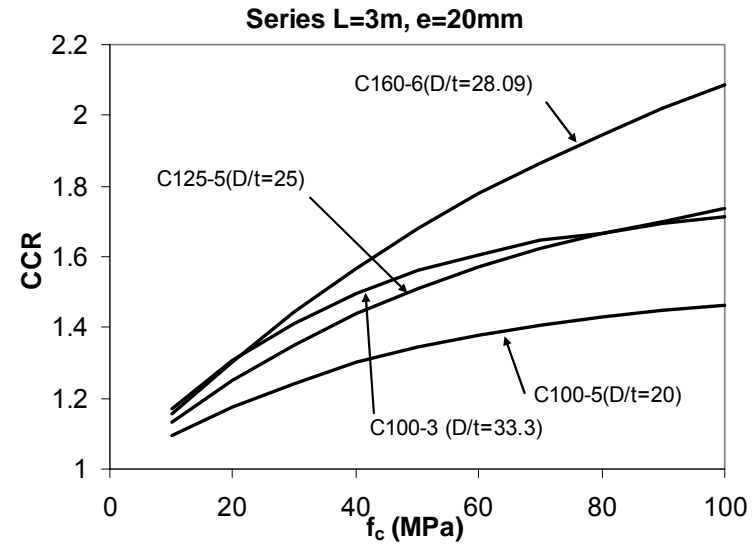

a)

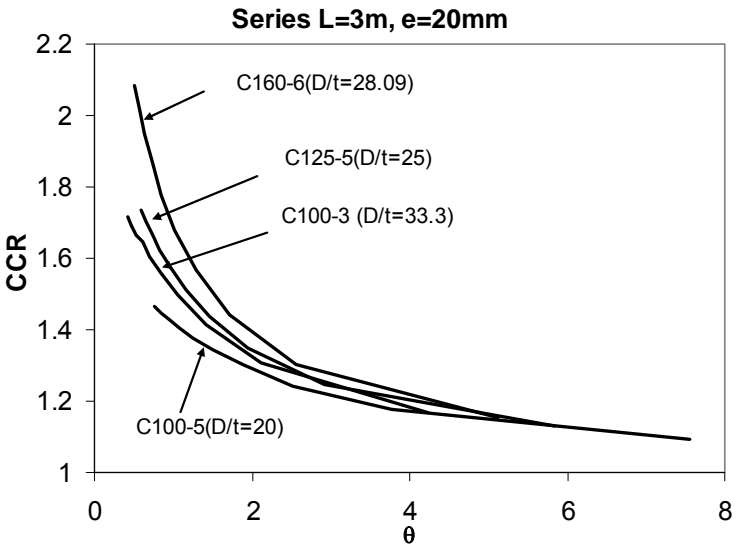

c)

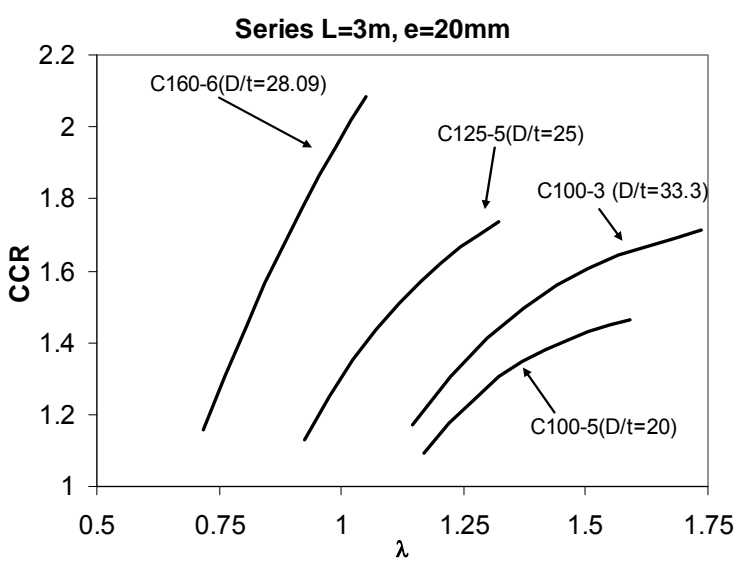

e)

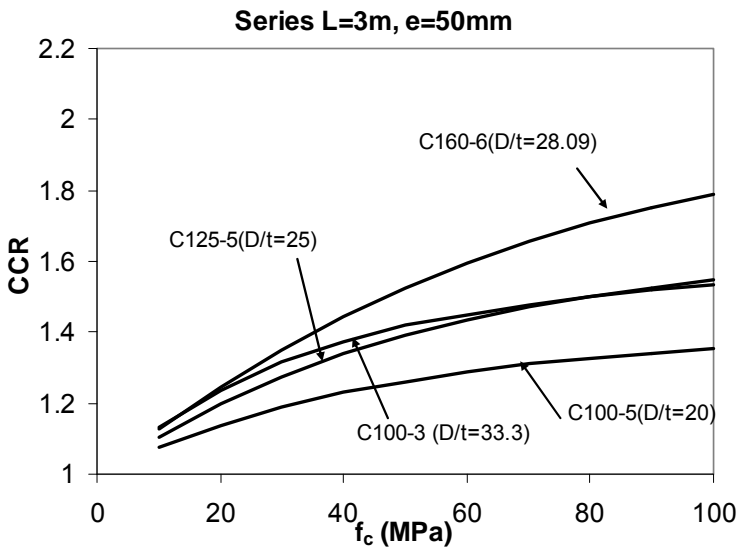

b)

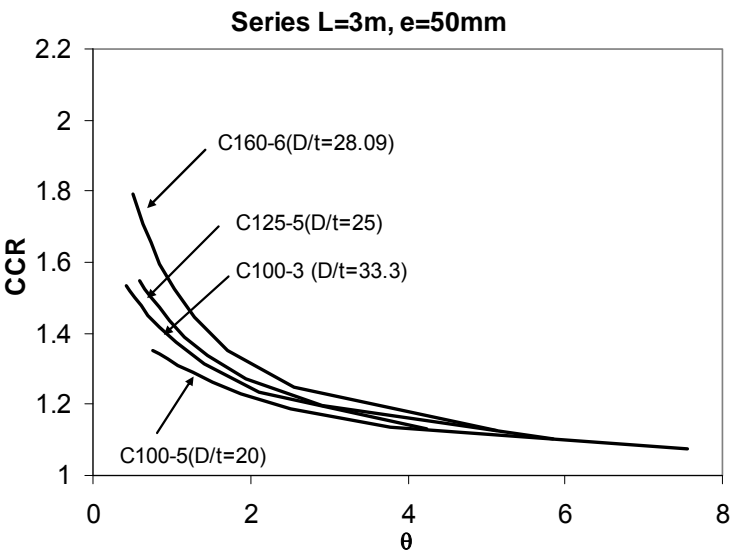

d)

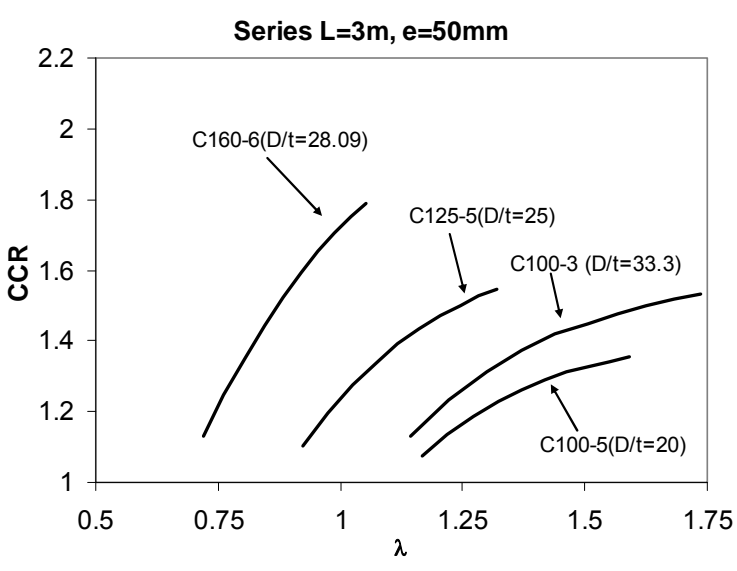

f)

Figure 9. Concrete contribution ratio $(\mathrm{CCR})$ in the cases with $\mathrm{L}=3 \mathrm{~m}$ in parametric study "Step A". 
Portolés J1, Romero ML*, Filippou FC and Bonet JL, Simulation and design recommendations of eccentrically loaded slender concrete-filled tubular columns, Engineering Structures 2011: 33 (5), pp. 1576-1593.

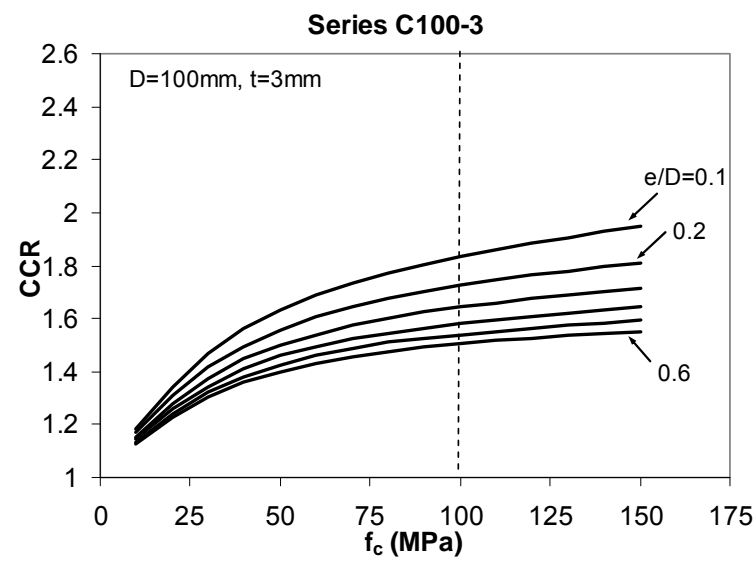

a)

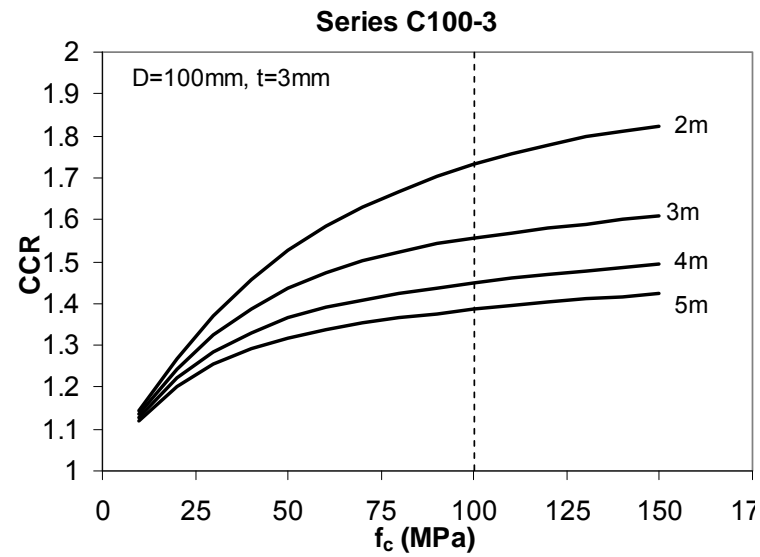

c)

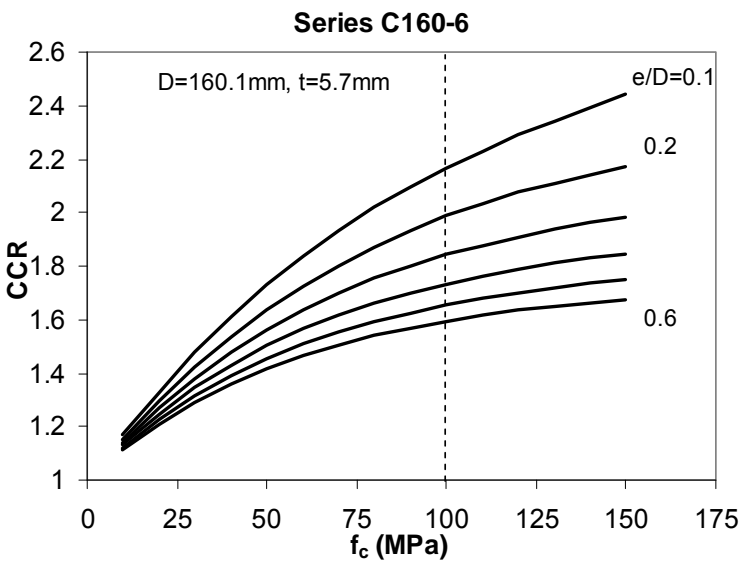

b)

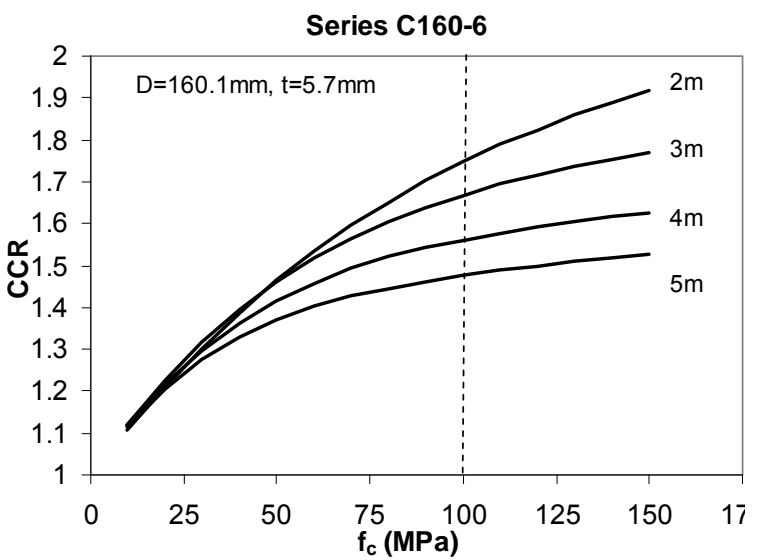

d)

Figure 10. Influence of the strength of concrete $(\mathrm{fc})$ on the concrete contribution ratio $(\mathrm{CCR})$ :

a) and b) for parametric study B (influence of eccentricity), c) and d) for parametric study C (influence of length). 
Portolés J1, Romero ML*, Filippou FC and Bonet JL, Simulation and design recommendations of eccentrically loaded slender concrete-filled tubular columns, Engineering Structures 2011: 33 (5), pp. 1576-1593.

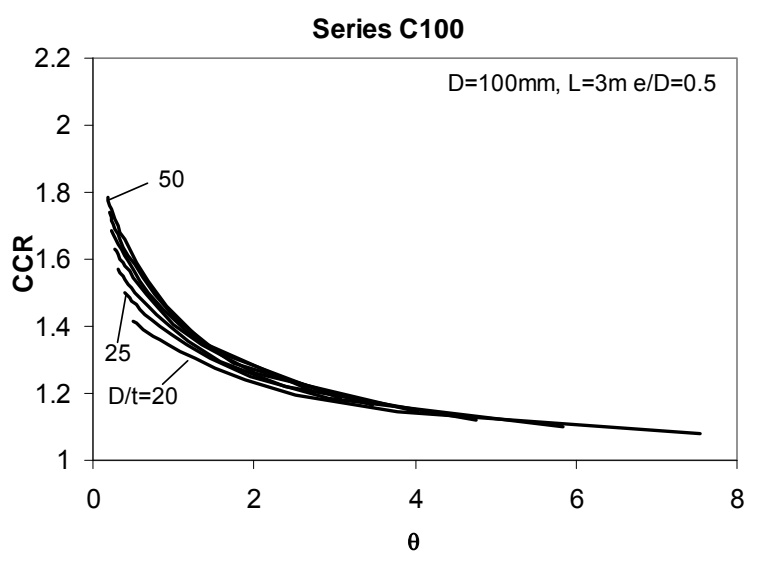

a)

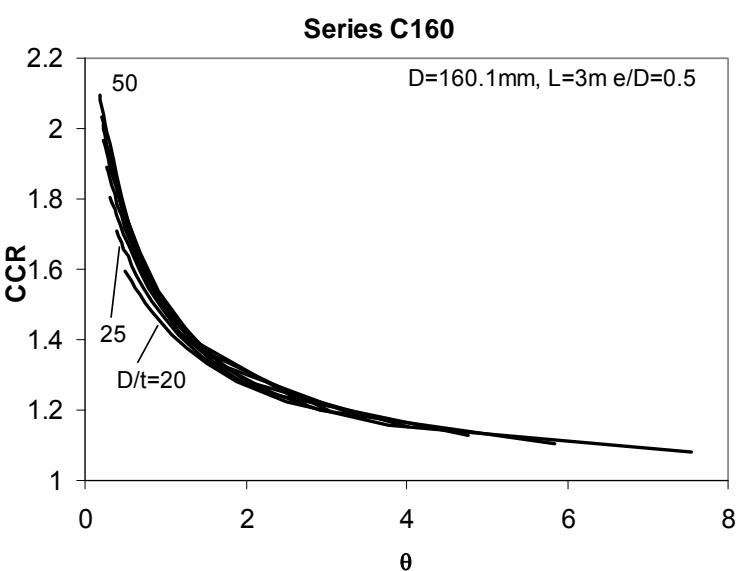

b)

Figure 11. Concrete contribution ratio (CCR) versus the confinement index $(\theta)$ in parametric study D (influence of ratio $\mathrm{D} / \mathrm{t}$ ). 
Portolés J1, Romero ML*, Filippou FC and Bonet JL, Simulation and design recommendations of eccentrically loaded slender concrete-filled tubular columns, Engineering Structures 2011: 33 (5), pp. 1576-1593.

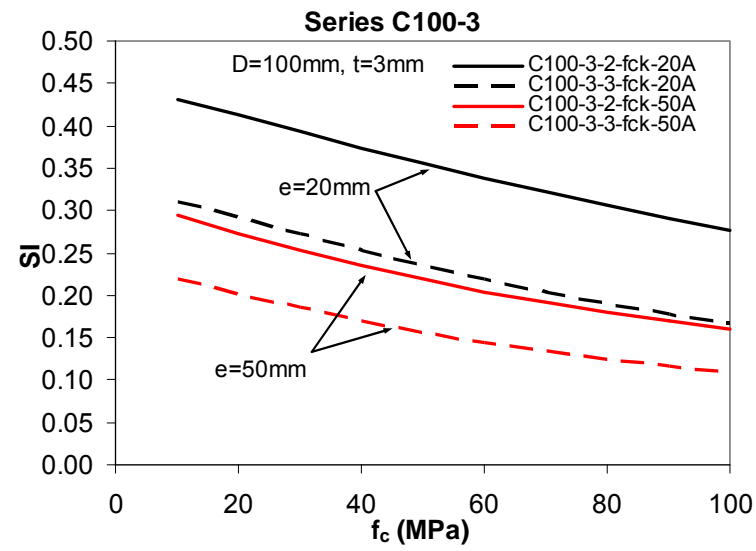

a)

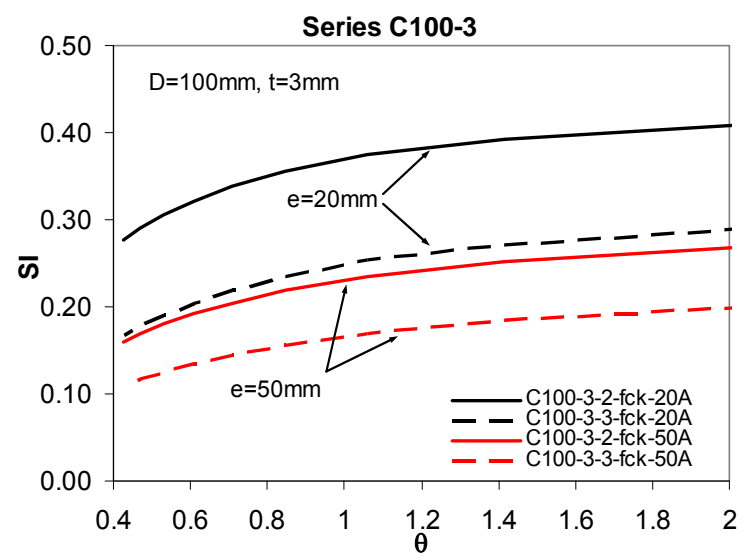

c)

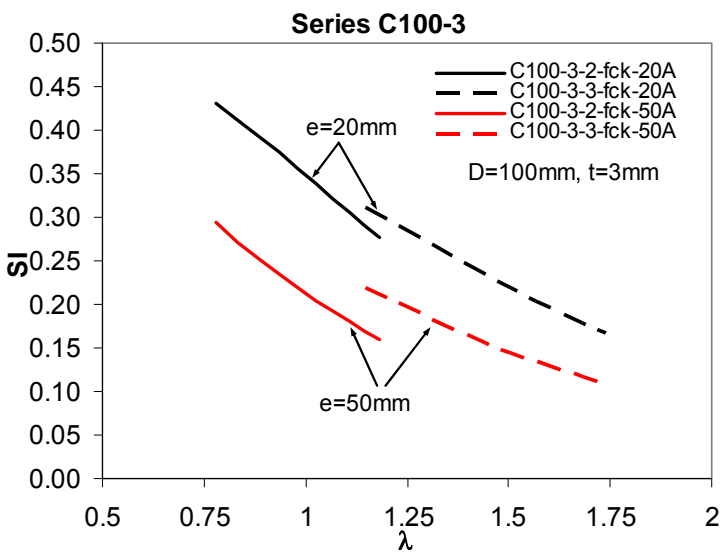

e)

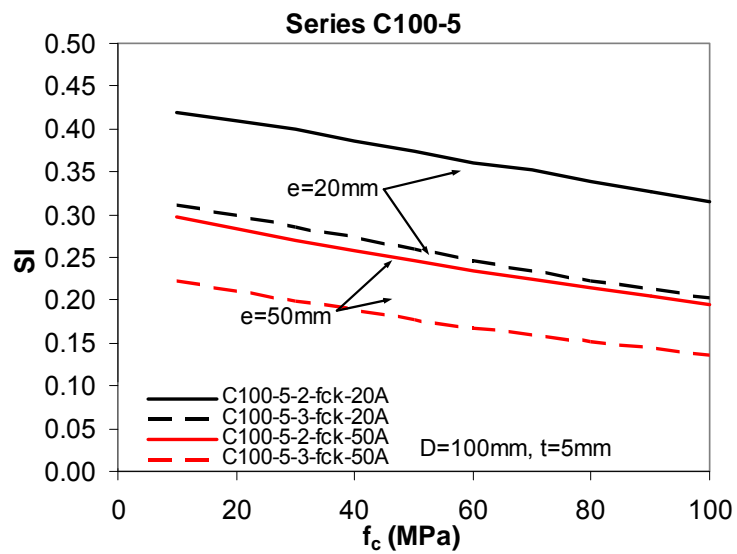

b)

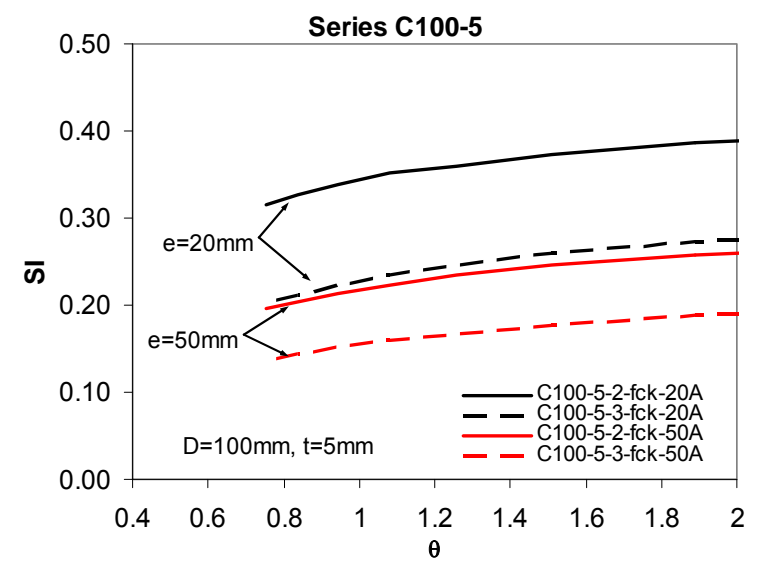

d)

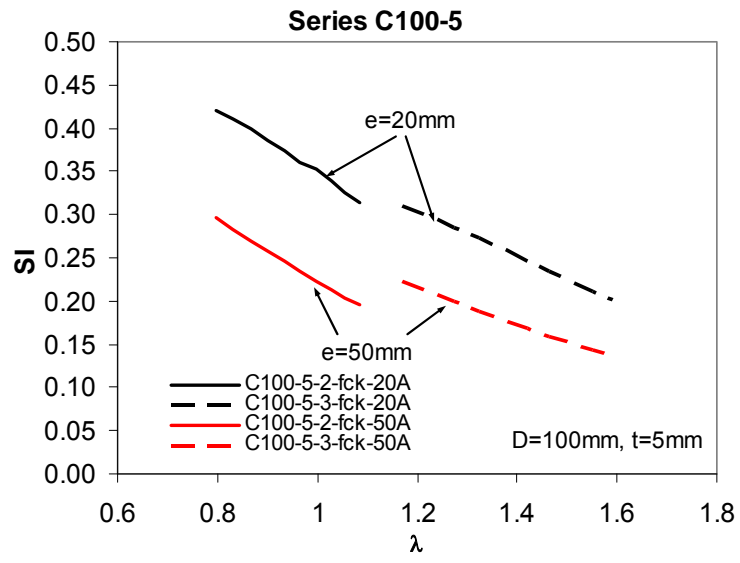

f)

Figure 12. Strength Index (SI) of cases with $\mathrm{D}=100 \mathrm{~mm}$ in parametric study "Step A". 
Portolés J1, Romero ML*, Filippou FC and Bonet JL, Simulation and design recommendations of eccentrically loaded slender concrete-filled tubular columns, Engineering Structures 2011: 33 (5) , pp. 1576-1593.

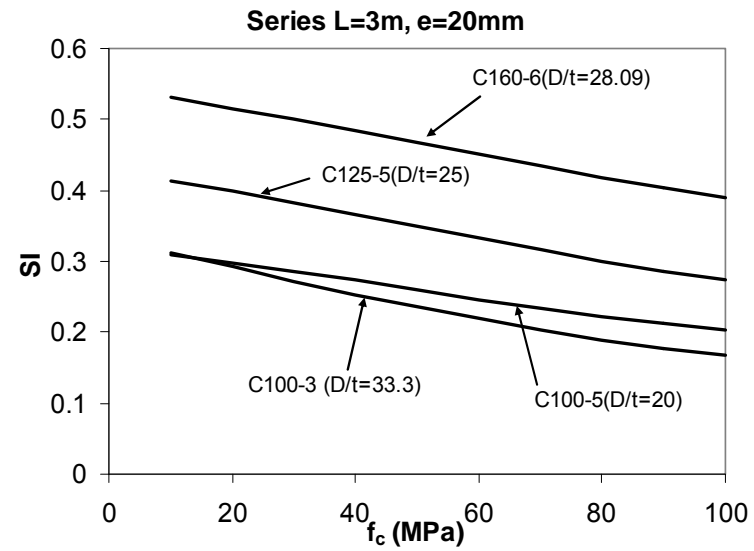

a)

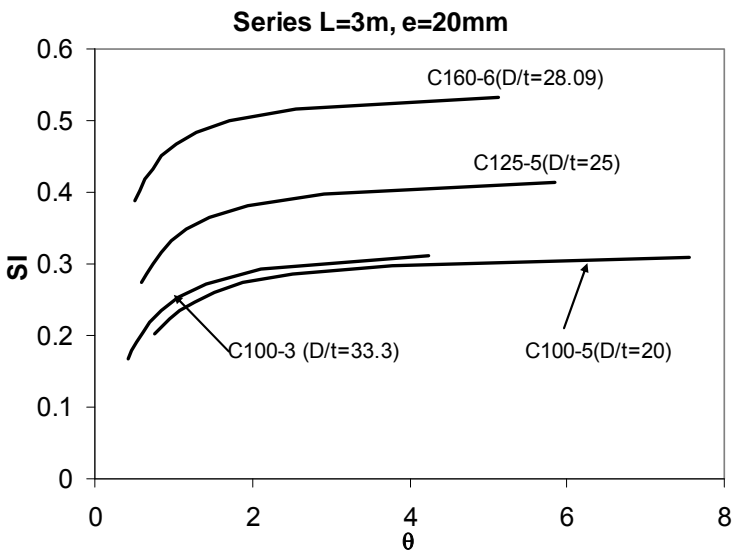

c)

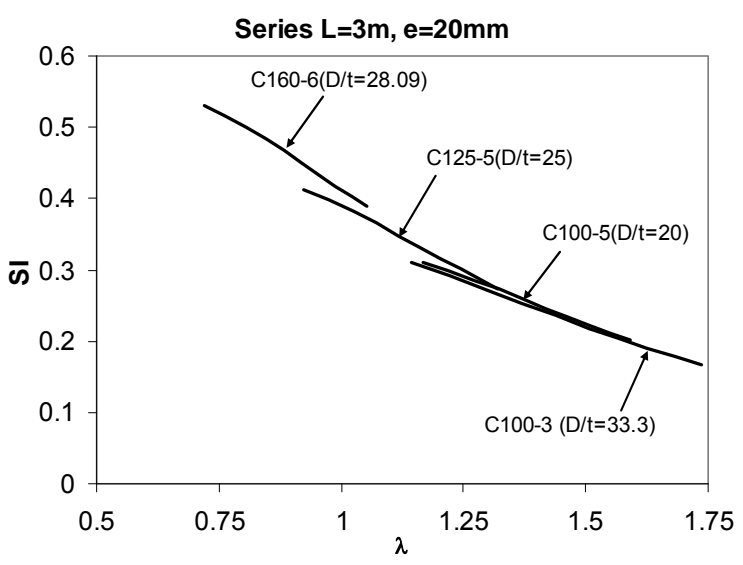

e)

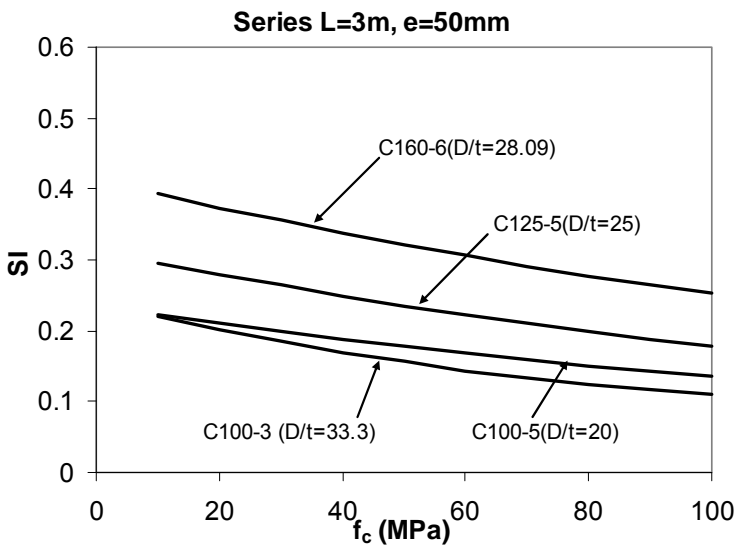

b)

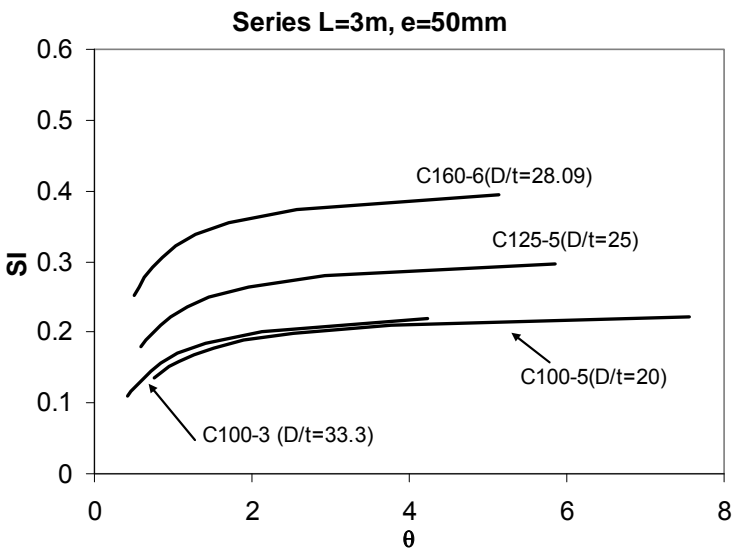

d)

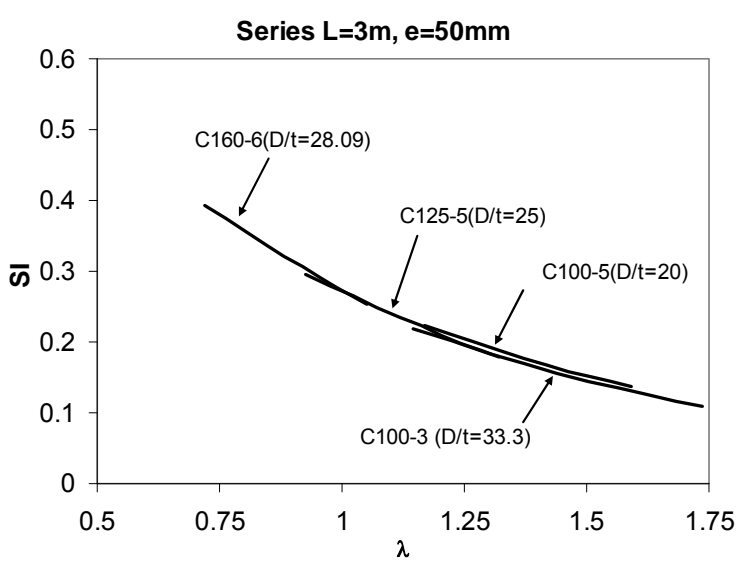

f)

Figure 13. Strength Index (SI) of cases with $\mathrm{L}=3 \mathrm{~m}$ in parametric study "Step A". 
Portolés J1, Romero ML*, Filippou FC and Bonet JL, Simulation and design recommendations of eccentrically loaded slender concrete-filled tubular columns, Engineering Structures 2011: 33 (5), pp. 1576-1593.

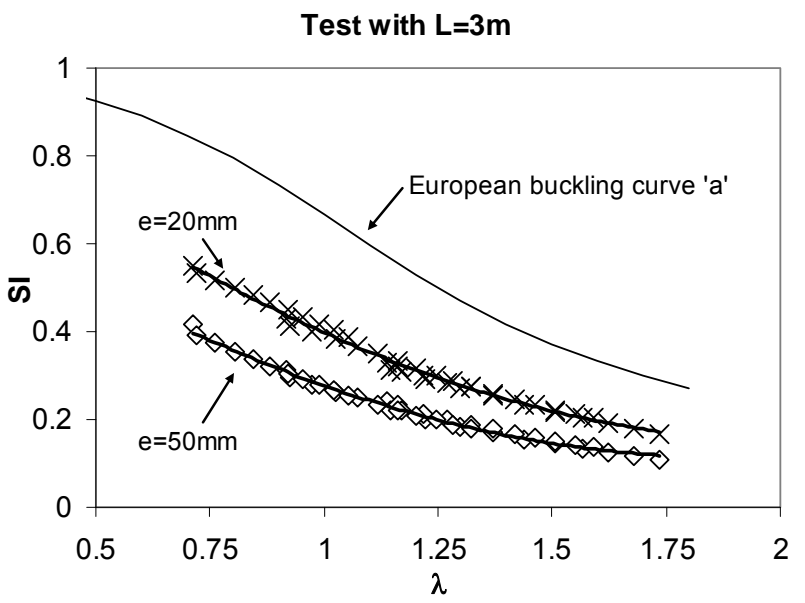

Figure 14. Comparison between the European buckling curve and the strength index (SI) for all columns in parametric study A with $\mathrm{L}=3 \mathrm{~m}$. 
Portolés Jl, Romero ML*, Filippou FC and Bonet JL, Simulation and design recommendations of eccentrically loaded slender concrete-filled tubular columns, Engineering Structures 2011: 33 (5) , pp. 1576-1593.

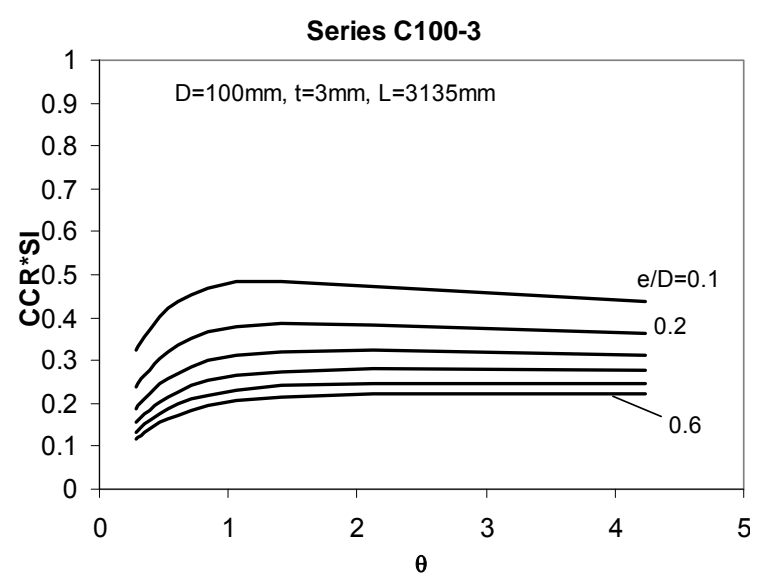

a)

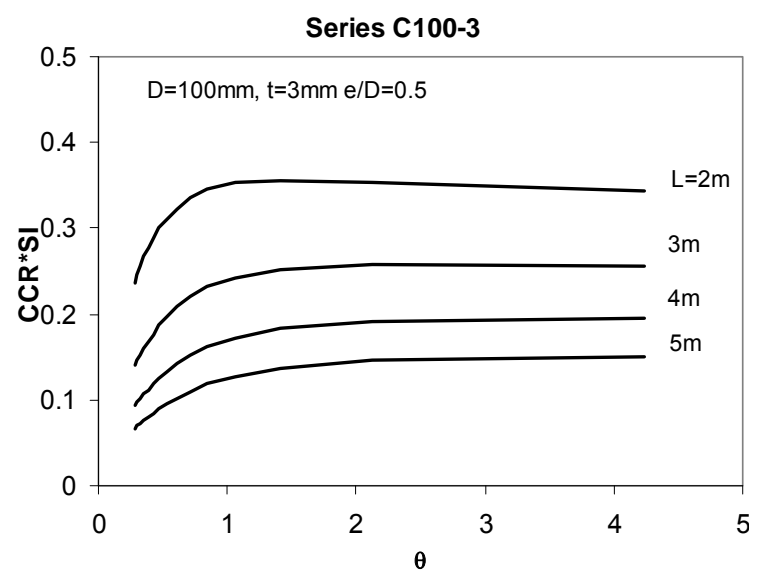

c)

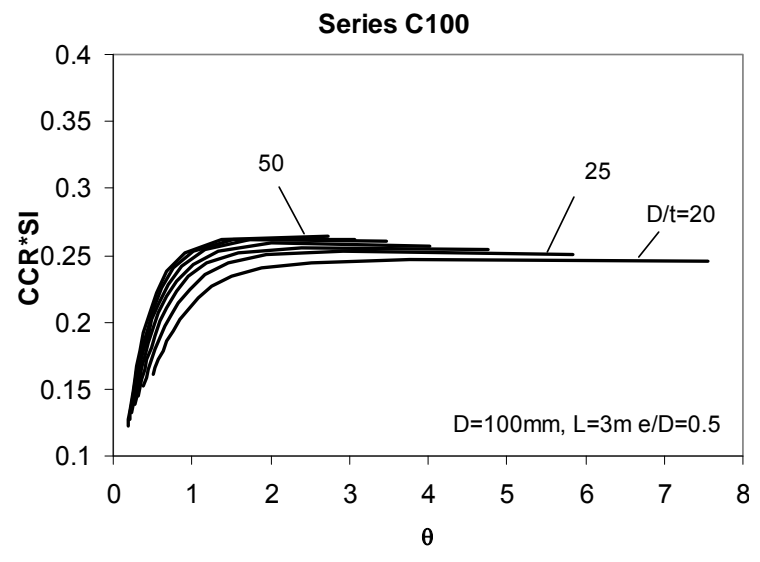

e)

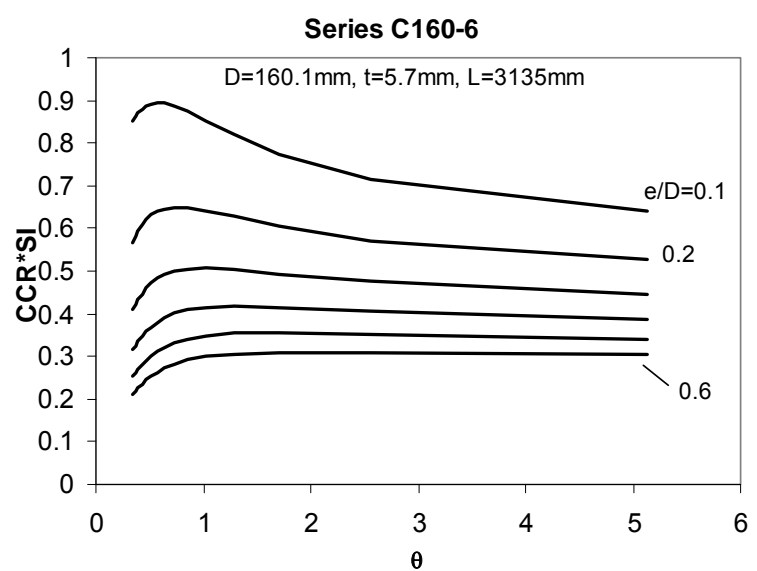

b)

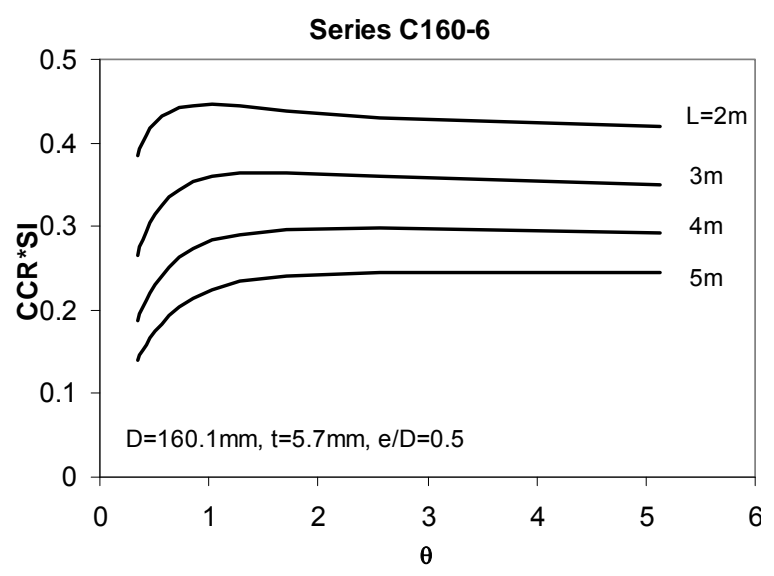

d)

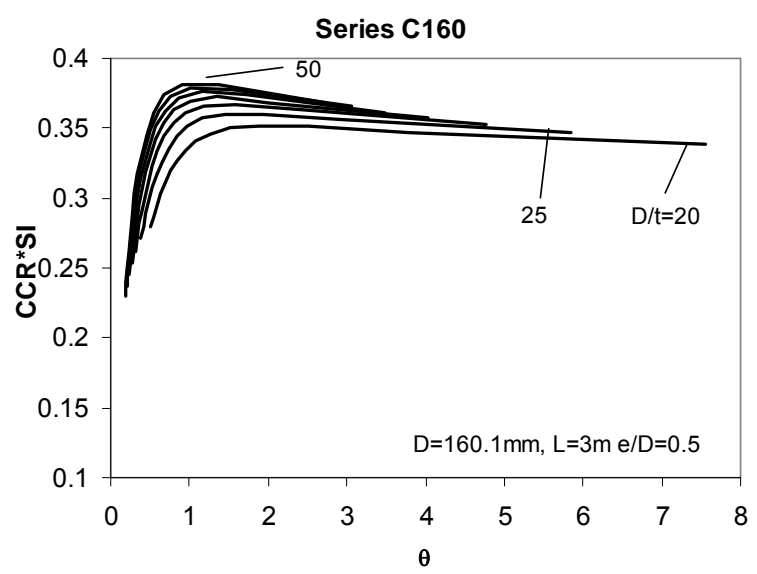

f)

Figure 15. Effect of the confinement index $(\theta)$ versus the product $\mathrm{CCR}^{*} \mathrm{SI}$ for parametric studies B, C, and D. 
Portolés Jl, Romero ML*, Filippou FC and Bonet JL, Simulation and design recommendations of eccentrically loaded slender concrete-filled tubular columns, Engineering Structures 2011: 33 (5), pp. 1576-1593.

Table 1. Test properties and results

\begin{tabular}{|c|c|c|c|c|c|c|c|c|c|c|}
\hline est & $\begin{array}{c}\mathrm{D} \\
(\mathrm{mm})\end{array}$ & $\begin{array}{c}t \\
(\mathrm{~mm})\end{array}$ & $\begin{array}{c}\mathrm{L} \\
(\mathrm{mm})\end{array}$ & $\begin{array}{c}\mathrm{e} \\
(\mathrm{mm})\end{array}$ & $\bar{\lambda}$ & $\begin{array}{c}f_{c} \\
(\mathrm{MPa}) \\
\end{array}$ & $\begin{array}{c}\mathbf{N}_{\max , \operatorname{Exp}} \\
(\mathbf{k N})\end{array}$ & $\begin{array}{c}\mathrm{N}_{\max , \mathrm{Num}} \\
(\mathbf{k N})\end{array}$ & $\xi$ & $\begin{array}{c}\mathrm{N}_{\mathrm{u}, \mathrm{EC} 4} \\
(\mathrm{kN})\end{array}$ \\
\hline C100-3-2-30-20-2 & 100 & 3 & 2135 & 20 & 0.77 & 32.7 & 181.56 & 202.19 & 0.90 & 203.49 \\
\hline C100-3-2-30-50-1 & 100 & 3 & 2135 & 50 & 0.82 & 34.5 & 117.49 & 128.56 & 0.91 & 126.60 \\
\hline C100-3-2-70-20-1 & 100 & 3 & 2135 & 20 & 0.90 & 65.79 & 248.58 & 246.51 & 1.01 & 240.23 \\
\hline C100-3-2-70-50-1 & 100 & 3 & 2135 & 50 & 0.91 & 71.64 & 151.59 & 147.95 & 1.02 & 139.58 \\
\hline C100-3-2-90-20-1 & 100 & 3 & 2135 & 20 & 1.05 & 95.63 & 271.04 & 271.18 & 1.00 & 255.69 \\
\hline C100-3-2-90-50-1 & 100 & 3 & 2135 & 50 & 1.07 & 93.01 & 154.24 & 154.43 & 1.00 & 144.19 \\
\hline C100-3-3-00-20-1 & 100 & 3 & 3135 & 20 & 1.17 & 0 & 115.66 & 105.37 & 1.10 & \\
\hline C100-3-3-00-50-1 & 100 & 3 & 3135 & 50 & 1.16 & 0 & 82.32 & 75.83 & 1.09 & \\
\hline C100-3-3-30-20-1 & 100 & 3 & 3135 & 20 & 1.37 & 39.43 & 140.32 & 144.39 & 0.97 & 143.19 \\
\hline C100-3-3-30-50-1 & 100 & 3 & 3135 & 50 & 1.35 & 36.68 & 93.75 & 94.96 & 0.99 & 96.72 \\
\hline C100-3-3-70-20-1 & 100 & 3 & 3135 & 20 & 1.58 & 71.74 & 159.55 & 159.74 & 1.00 & 152.90 \\
\hline C100-3-3-70-50-1 & 100 & 3 & 3135 & 50 & 1.62 & 79.55 & 102.75 & 104.71 & 0.98 & 104.86 \\
\hline C100-3-3-90-20-1 & 100 & 3 & 3135 & 20 & 1.71 & 94.56 & 160.33 & 165.84 & 0.97 & 157.41 \\
\hline C100-3-3-90-50-1 & 100 & 3 & 3135 & 50 & 1.68 & 90.4 & 106.80 & 106.12 & 1.01 & 106.31 \\
\hline C100-5-2-00-20-1 & 102 & 5 & 135 & 20 & 0.79 & 0 & 223.37 & 211.81 & 1.05 & \\
\hline C100-5-2-00-20-2 & 102 & 5 & 35 & 20 & 0.88 & 0 & 226.61 & 1.81 & 1.07 & \\
\hline C100-5-2-00-50-1 & 100 & 5 & 135 & 50 & 1.00 & 0 & 142.19 & 137.73 & 1.03 & \\
\hline C100-5-2-3 & 100 & 5 & 2135 & 20 & 0.97 & 35.39 & 270.02 & 265.19 & 1.02 & 278.6 \\
\hline $0-1$ & 100 & 5 & 2135 & 50 & 0.77 & 30.54 & & 87 & 0.96 & 177. \\
\hline $20-1$ & 100 & 5 & 2135 & 20 & 0.77 & 70.16 & 31 & 77 & 1.02 & 324.95 \\
\hline C100-5-2-9 & 102 & 5 & 2135 & 20 & 1.05 & 95.43 & 330 & 358.56 & 0.92 & 362.45 \\
\hline C100-5-2-90-50-1 & 102 & 5 & 2135 & 50 & 1.02 & 81.66 & 213 & .28 & 1.00 & 212.17 \\
\hline C100-5-3-3 & 102 & 5 & 3135 & 20 & 1.29 & 38.67 & 212 & 37 & 1.03 & 209.32 \\
\hline C100-5-3-3 & 102 & 5 & 3135 & 50 & 1.30 & 39.56 & 144 & 140.89 & 1.03 & 146.51 \\
\hline C100 & 102 & 5 & 3135 & 20 & 1.45 & 71.86 & 23 & 24 & 1.03 & 226.23 \\
\hline C100 & 102 & 5 & 5 & 50 & 1.45 & 72.49 & 15 & 92 & 1.01 & 155.50 \\
\hline C100-5-3-90-20-1 & 102 & 5 & 3135 & 20 & 1.51 & 86.39 & 24 & 229.20 & 1.08 & 229.77 \\
\hline C100-5-3-90-50-1 & 102 & 5 & 3135 & 50 & 1.55 & 96.74 & 164.95 & 155.03 & 1.06 & 159.64 \\
\hline C125-5-3-90-20-1 & 125 & 5 & 35 & 20 & 1.28 & 87.98 & 47 & 437.35 & 1.08 & 428.81 \\
\hline C125-5-3-90-50-1 & 125 & 5 & 3135 & 50 & 1.31 & 96.97 & 317.90 & 289.98 & 1.10 & 284.71 \\
\hline C125-5-3-90-20-2 & 125 & 5 & 3135 & 20 & 1.35 & 107.3 & 489.47 & 452.79 & 1.08 & 437.93 \\
\hline C125-5-3-90-50-2 & 125 & 5 & 3135 & 50 & 1.31 & 97.92 & 322.97 & 290.32 & 1.11 & 285.01 \\
\hline C160-6-3-9 & 160 & 5.7 & 3135 & 20 & 1.01 & 87.38 & 1012.47 & 970.89 & 1.04 & 933.15 \\
\hline $0-6-3-70-50-1$ & 160 & 5.7 & 3135 & 50 & 0.97 & 74.75 & 642.16 & 615.75 & 1.04 & 600.71 \\
\hline C160-6-3-90-20-2 & 160 & 5.7 & 3135 & 20 & 1.00 & 83.08 & 1011.52 & 956.16 & 1.06 & 919.49 \\
\hline \multirow[t]{3}{*}{ C160-6-3-90-50-1 } & 160 & 5.7 & 3135 & 50 & 1.05 & 98.5 & 686.21 & 654.65 & 1.05 & 622.82 \\
\hline & & & & & & & & Mean & 1.02 & \\
\hline & & & & & & & & Dev & 0.05 & \\
\hline
\end{tabular}


Portolés J1, Romero ML*, Filippou FC and Bonet JL, Simulation and design recommendations of eccentrically loaded slender concrete-filled tubular columns, Engineering Structures 2011: 33 (5), pp. 1576-1593.

Table 2. Variation of the parameters for experimental tests from the literature.

\begin{tabular}{lc}
\hline \multicolumn{1}{c}{ Parameter } & Range \\
\hline Slenderness $(L / D)$ & $7.95-31.61$ \\
Relative slenderness $(\bar{\lambda})$ & $0.5-1.4$ \\
Relative eccentricity $(e / D)$ & $0.05-0.5$ \\
$f_{c}(\mathrm{MPa})$ & $23-102$ \\
$f_{y}(\mathrm{MPa})$ & $193-435$ \\
\hline
\end{tabular}


Portolés J1, Romero ML*, Filippou FC and Bonet JL, Simulation and design recommendations of eccentrically loaded slender concrete-filled tubular columns, Engineering Structures 2011: 33 (5), pp. 1576-1593.

Table 3. Results of the verification of the model for experimental tests from the literature.

\begin{tabular}{lcccccc}
\hline \multirow{2}{*}{ Authors } & \multirow{2}{*}{$\begin{array}{c}\text { Number } \\
\text { of Tests }\end{array}$} & \multicolumn{4}{c}{ Numerical model } \\
\cline { 3 - 7 } & $\xi_{m}$ & V.C & $\xi_{\max }$ & $\xi_{\min }$ \\
\hline Zeghiche and Chaoui (2005) [34] & 8 & 1 & 0.03 & 1.04 & 0.96 \\
\hline Rangan and Joyce (1992) [35] & 9 & 0.99 & 0.15 & 1.34 & 0.83 \\
\hline $\begin{array}{l}\text { Neogi et al } \\
\text { (1969) [36] }\end{array}$ & 18 & 1.10 & 0.15 & 1.49 & 0.89 \\
\hline Kilpatrick and Rangan (1999)[37] & 17 & 0.97 & 0.07 & 1.13 & 0.88 \\
\hline All & $\mathbf{5 2}$ & $\mathbf{1 . 0 2}$ & $\mathbf{0 . 1 3}$ & $\mathbf{1 . 4 9}$ & $\mathbf{0 . 8 3}$ \\
\hline
\end{tabular}


Portolés J1, Romero ML*, Filippou FC and Bonet JL, Simulation and design recommendations of eccentrically loaded slender concrete-filled tubular columns, Engineering Structures 2011: 33 (5), pp. 1576-1593.

Table 4. Parametric studies

\begin{tabular}{|c|c|}
\hline \multicolumn{2}{|c|}{$\begin{array}{l}\text { Step A } \\
\text { Effect of the strength of concrete }\end{array}$} \\
\hline Section & C100-3, C100-5, C125-5, C160.1-5.7 \\
\hline $\mathrm{L}$ & $2135 \mathrm{~mm}, 3135 \mathrm{~mm}$ \\
\hline $\mathrm{E}$ & $20 \mathrm{~mm}, 50 \mathrm{~mm}$ \\
\hline$f_{y}$ & $322 \mathrm{MPa}$ \\
\hline$f_{c}$ & $10,20, \ldots, 100 \mathrm{MPa}$ \\
\hline \multirow{2}{*}{\multicolumn{2}{|c|}{$\begin{array}{l}\text { Step B } \\
\text { Effect of the eccentricity }\end{array}$}} \\
\hline & \\
\hline $\mathrm{L}$ & $3135 \mathrm{~mm}$ \\
\hline $\mathrm{e} / \mathrm{D}$ & $0.1,0.2, \ldots, 0.6$ \\
\hline$f_{y}$ & $322 \mathrm{MPa}$ \\
\hline$f_{c}$ & $10,20, \ldots, 150 \mathrm{MPa}$ \\
\hline \multicolumn{2}{|c|}{$\begin{array}{l}\text { Step C } \\
\text { Effect of the length and geometrical slenderness L/D }\end{array}$} \\
\hline Section & $\mathrm{C} 100-3, \mathrm{C} 160.1-5.7 ; \mathrm{D} / \mathrm{t}=33.3$ and 28.08 respectively \\
\hline $\mathrm{L}$ & $1.5,2,3,4,5 \mathrm{~m}$ \\
\hline $\mathrm{e} / \mathrm{D}$ & 0.5 \\
\hline $\mathrm{f}_{\mathrm{y}}$ & $322 \mathrm{MPa}$ \\
\hline$f_{c}$ & $10,20, \ldots, 150 \mathrm{MPa}$ \\
\hline \multicolumn{2}{|c|}{$\begin{array}{l}\text { Step } D \\
\text { Effect of the ratio } D / t\end{array}$} \\
\hline $\mathrm{D}$ & $100,160.1 \mathrm{~mm}$ \\
\hline $\mathrm{D} / \mathrm{t}$ & $20,25,30,35,40,45,50$ \\
\hline $\mathrm{L}$ & $3 \mathrm{~m}$ \\
\hline $\mathrm{e} / \mathrm{D}$ & 0.5 \\
\hline$f_{y}$ & $322 \mathrm{MPa}$ \\
\hline$\frac{f_{c}}{f_{c}}$ & $10,20, \ldots, 150 \mathrm{MPa}$ \\
\hline
\end{tabular}

